\title{
Mechanical Characteristics and Structure of Highly Deformed Zinc
}

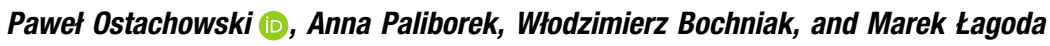

Submitted: 23 April 2021 / Revised: 27 November 2021 / Accepted: 30 November 2021 / Published online: 12 January 2022

\begin{abstract}
The paper contains a set of experimental data on the influence of the KOBO extrusion (extrusion with simultaneous cyclic torsion) on mechanical properties of pure zinc and proves that they can be controlled in order to achieve the desired final values, while tensile characteristics may either show monotonic course or contain the Lüders-type effect. It has been found that the mechanical properties of the KOBO extruded zinc are not linked to the grain size, thus proving the hypothesis about the dominating role of over-equilibrial concentration of point defects (including their clusters).
\end{abstract}

Keywords grains versus point defects, KOBO extrusion, pure zinc, structure and mechanical properties

\section{Introduction}

The main objective of SPD (severe plastic deformation) methods is a radical refinement of grains in metallic materials, in particular - a reduction of typical grain size from several dozen or several hundreds of micrometers into a nanometer scale (Ref 1-3). It is widely known that nano-metals have very attractive mechanical properties, including very high strengthening and increased plasticity at low temperatures and superplasticity at higher temperature values.

Low-temperature KOBO extrusion is one of the SPD methods (Ref 4, 5). However, it has been proved that metals undergoing this process do not have to meet the grain size criterion in order to acquire extreme mechanical properties (Ref 6). What is more, results of experimental research on the evolution of structure during the KOBO process suggest a dominant role of mechanically generated point defects, mainly self-interstitial atoms, the concentration of which exceeds the equilibrium by many levels of magnitude (Ref 6, 7). This phenomenon results from a change in the deformation path, which leads to instability of the dislocation structure and subsequently, to strong local deformity of the crystal lattice (Ref 8). In other words, as a result of slip dislocations crossing the forest dislocation, vast numbers of point defects are generated in simultaneously created shear bands. Next, a part of the thermodynamically unstable over-equilibrial point defects undergo immediate annihilation at grain boundaries or on the metal surface, while others evolve into low-energy nano-

Paweł Ostachowski, Anna Paliborek, and Włodzimierz Bochniak, Faculty of Non-Ferrous Metals, AGH - University of Science and Technology, A. Mickiewicza Av. 30, 30-059 Cracow, Poland; and Marek Lagoda, Łukasiewicz Research Network - Institute of NonFerrous Metals, Sowińskiego St. 5, 44-100 Gliwice, Poland. Contact e-mail: pawel.ostachowski@agh.edu.pl. sized clusters (Ref 6). The clusters are responsible for high strengthening of the metal product (Ref 9-12), but if destroyed due to thermal or mechanical stimulus, in the form of point defects can again saturate the metal (as during the KOBO extrusion) reducing its flow stress. It can be assumed that the microstructure evolves in this way whenever the deformation path changes; however, during the KOBO process it seems qualitatively and quantitatively most striking. In this context, the generation of fine/nano-sized grains can be considered as the KOBO extrusion 'side effect.' Moreover, it appears that regardless of the scheme of the change in deformation path (e.g., in various SPD methods), the mechanism responsible for the mechanical properties of the final products is the same, although highly deformed crystalline structure in the active shear bands evolves into polycrystalline aggregate, the grains of which consist of a vast number of point defect clusters. The paper (Ref 6) proves the durability of clusters generated in metals as a result of the KOBO extrusion even after later recrystallization and grain expansion processes.

From a physical point of view, it seems obvious that mechanical instability can only occur in the deformed metals when the deformation process is organized in time and space (shear bands). The phenomenon can be very clearly observed during tensile tests, when the shear bands propagate through most, if not all of the cross section of the sample (Lüders band, the Portevin-Le Chatelier effect, initiation and neck development). Interestingly, the occurrence of shear bands is not exclusive to crystalline materials, as they are also present in metallic glasses, influencing their mechanical properties, as 'the critical stress for initiating a shear band determines the upper limit of yield stress, while the density of shear band and the critical failure condition of shear band control the global plasticity of metallic glasses' (Ref 13).

But is mechanical instability an inevitable consequence of the shear bands activity? The scale of the phenomenon seems to be the deciding factor here. If the shear bands are dense and small (thin and short), the process is fairly lengthy, and the stress-strain curve can be smooth and monotonic. The historical interpretation of Lüders effect as a result of the interaction between dislocations and the Cottrell's atmospheres is not to be proved true by the next experimental data, confirming the 
Table 1 Chemical composition (wt.\%) of zinc used for the research

\begin{tabular}{lccccc}
\hline $\mathbf{Z n}$ & $\mathbf{P b}$ & $\mathbf{C d}$ & $\mathbf{F e}$ & $\mathbf{C u}$ & Sn \\
\hline Balance & 0.003 & 0.0001 & 0.0006 & 0.0004 & 0.0001 \\
\hline
\end{tabular}

occurrence of the same mechanical effect in pure metals (Ref 14-19). Therefore, today, mechanical instability is considered to be linked to the occurrence of ultra-fine or nano-sized grains (Ref 18, 20-23).

This poses the question of possible reactions of pure zinc extruded by the KOBO method during a tensile test with regards to the Lüders-type mechanical instability and the instability connected to the maximum strain, as well as their links to the $\mathrm{KOBO}$ process parameters. It is worth pointing out that the Lüders phenomenon was observed in KOBO extruded pure zinc with the grain size of $40 \mu \mathrm{m}$ (Ref 6,24$)$ and papers (Ref 25-28) suggest that mechanical instability of the stretched metal is a result of strain localization in shear bands, which seems to be the dominant mechanism in the KOBO process.

It is curious why different processes, not only SPD deformation, but also conventional rolling with a significant strain (Ref 15, 29-31) as well as the KOBO extrusion result in identical mechanical reaction (Lüders instability), despite great differentiation in grain sizes . There are strong presumptions that the characteristics of metals which previously underwent intense plastic deformation largely depend on structural nanoelements in the form of point defects (particularly selfinterstitial atoms), their concentrations and finally their spatial distribution-clusters. All of the deformation methods mentioned above promote self or externally imposed change (changes) of the deformation path, resulting in the strain localization in shear bands, which are simultaneously 'oversaturated' with point defects (Ref 32). Such structure is the cause of mechanical instability (sudden drop in uniform deformation, including Lüders effect) during tensile tests.

For this paper, a number of investigations were carried out on zinc in order to measure its mechanical properties before and after the KOBO extrusion in relation to structural observations conducted with the use of optical and electron microscopy. The aim of the research was to find dependencies between zinc's mechanical properties, including its tensile characteristics (Lüders effect), and the plastic deformation conditions engaged during the KOBO process. In this context, particular attention was paid to the role of grain size and over-equilibrial concentrations of point defects generated during the KOBO process.

\section{The Experiment}

Billets made of pure zinc (99.995\%), the chemical composition of which is shown in Table 1, in the form of cylinders with the dimensions of $\varnothing 40 \times 50 \mathrm{~mm}$, were used as the research material. They were subjected to direct extrusion by the KOBO method (Fig. 1) on a press of $1.0 \mathrm{MN}$, extrusion ratio $\lambda=100$ (the product's diameter was $4 \mathrm{~mm}$ ) at room temperature and at three different rates of $0.1 ; 0.33$ and $0.5 \mathrm{~mm} / \mathrm{s}$. The die

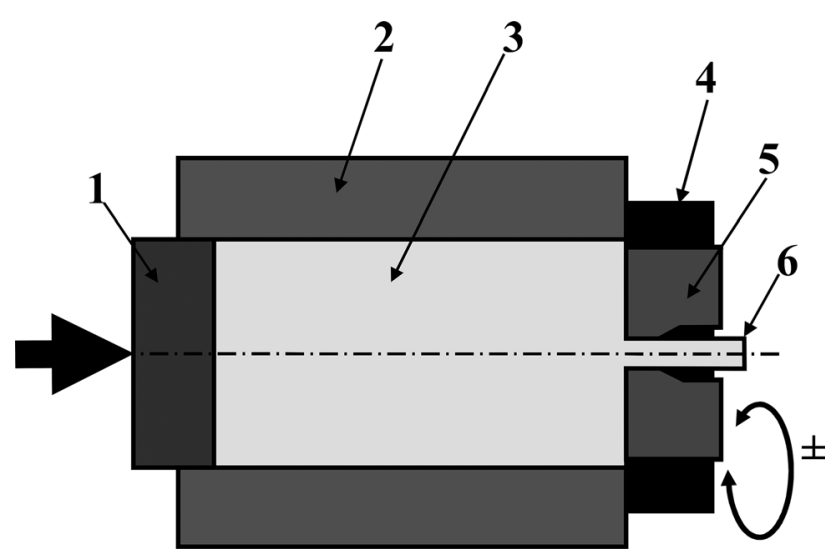

Fig. 1 Scheme of KOBO extrusion process: 1-punch, 2-container, 3-billet, 4-lock, 5-reversibly rotating die, 6 - extrudate (wire)

oscillation angle was $\pm 8^{\circ}$ each time and its frequency was constant for part of the tests and equaled 3, 5 or $8 \mathrm{~Hz}$.

Some of the billets were extruded under the conditions of constant press force (force exerted by punch) (Ref 6, 7), thanks to reduction of the initial die oscillation frequency $(3 ; 5$ or 8 $\mathrm{Hz}$ ) during the KOBO process. The press tools and products were cooled throughout the entire deformation procedure with cold water.

It is important to point out that earlier research on the KOBO extrusion of zinc (Ref 33 ) and analyzes of stress-strain curves of the obtained product have shown that the mechanical characteristics are either monotonic or unstable depending on the extrusion force level, which is highly controlled by the twisting frequency of the extruded metal and goes down with an increase in this parameter's value. This paper pays particular attention to this issue.

100 -mm-long samples (gauge length $50 \mathrm{~mm}$ ) were subjected to tensile test at the strain rates of $1 \times 10^{-4}$ to $9 \times 10^{-3} \mathrm{~s}^{-1}$, but also at a changing strain rate, which made it possible to assess its sensitivity parameter $m$ :

$m=\frac{d \ln \sigma}{d \ln \dot{\varepsilon}}$

where $m$ is the strain rate sensitivity, $\sigma$ is the flow stress and $\dot{\varepsilon}$ is the strain rate).

The results of tensile tests are presented as the dependencies between stress (force/initial cross section) and elongation (\%). Tensile tests were performed on the Zwick/Roell Z050 machine equipped with the testXexpert II software.

The samples were observed both in macro- and microscale with the use of optical and electron microscopy. In order to check the relations between the character of plastic flow and grain size, the last parameter was also measured. The samples for microscopic observations were first grinded with abrasive paper (with a grain size of 240 do 2000) and then polished with diamond suspensions (with the grain size of 9 to $0.1 \mu \mathrm{m}$ ), using dedicated Struers procedures. The obtained specimens were subsequently etched in a $10 \% \mathrm{HNO}_{3}$ solution. The observations were made on the NIKON Epiphot 200 optical microscope equipped with the NIS Elementes Analisis software.

Similar griding and polishing procedure was applied to prepare thin foils for electron microscopy observations. After the material reached the thickness of around $0.05-0.08 \mathrm{~mm}$, it 
was electrolytically polished on the Struers Tenupol 3 machine in the A2 electrolyte (at the voltage of 20-25 V and $2 \mathrm{~A}$ electricity). Prior to the observations, an additional ion thinning procedure on the Gatan 691 machine was performed. Electron microscopy observations were made on the JEOL 2010 field emission transmission electron microscope (TEM) operated at $200 \mathrm{kV}$ and equipped with the Gatan Orius software.

\section{Research Results}

\subsection{Mechanical Research}

Figure 2 shows the typical characteristics of the KOBO extrusion of zinc. The linear range of rapidly growing extrusion force, typical for the first stage of the process (curve 1), is linked to the billet's compression. The zinc begins to flow

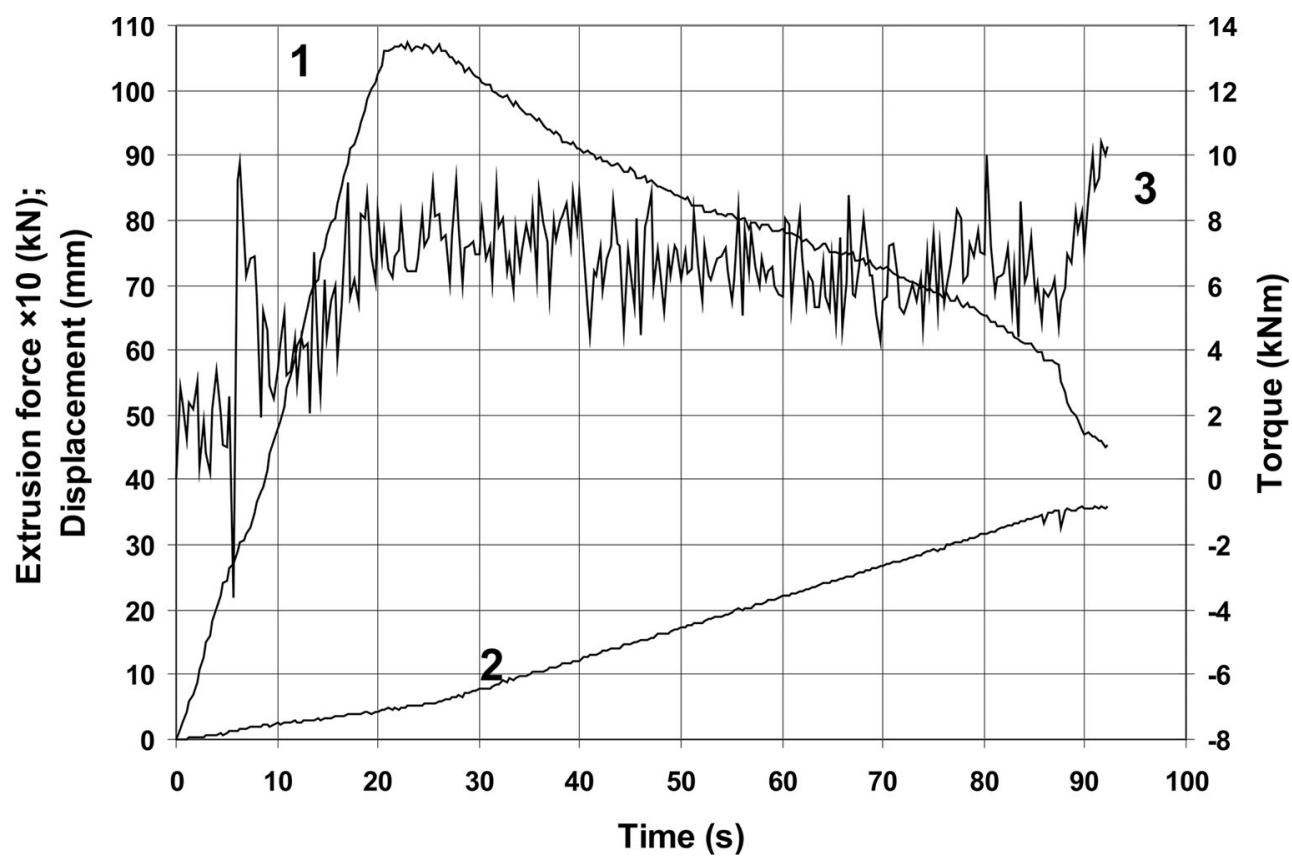

Fig. 2 Characteristics of the KOBO extrusion of zinc. Note: 1-extrusion force; 2 -displacement; 3 -torque

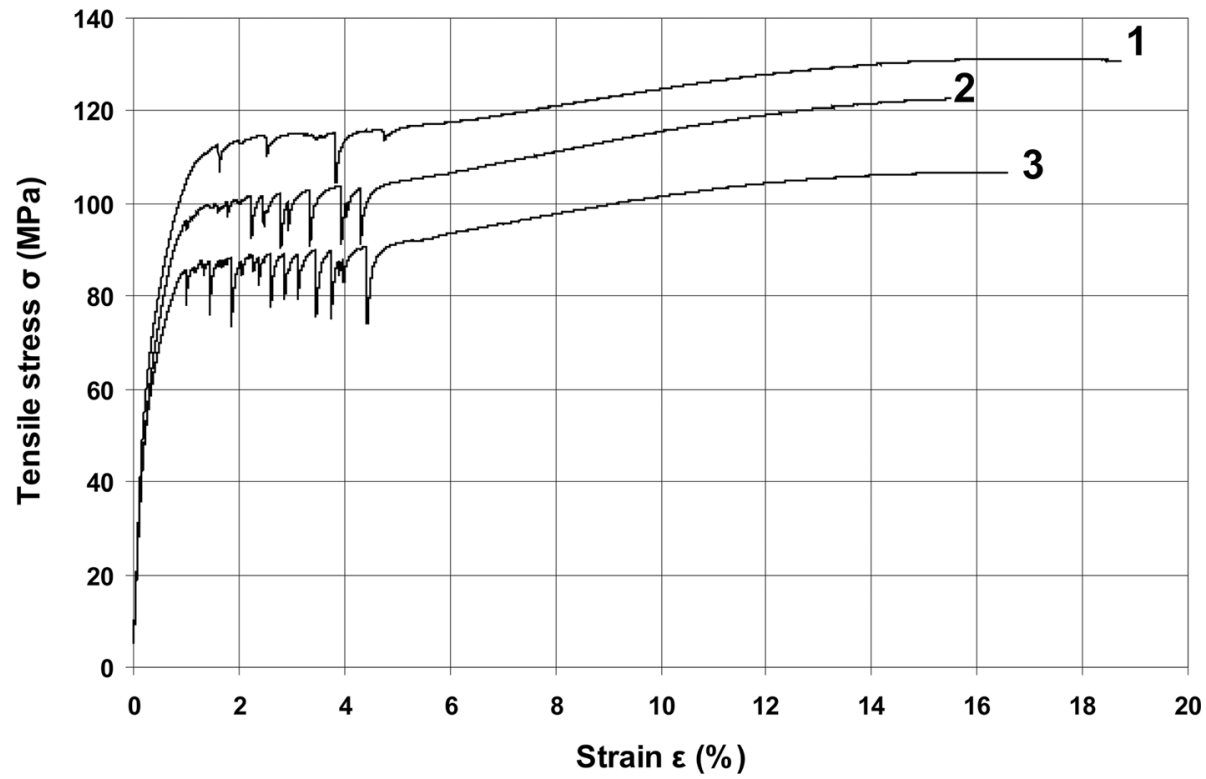

Fig. 3 Stress-strain curves for the KOBO extruded zinc with extrusion rate $0.1 \mathrm{~mm} / \mathrm{s}$, reverse die oscillation frequency $5 \mathrm{~Hz}$, extrusion force dropping from 700 to $500 \mathrm{kN}$. Strain rate during tensile test $\dot{\varepsilon}=5 \times 10^{-4} \mathrm{~s}^{-1}$. Samples taken from the beginning (1), middle (2) and end (3) sections of the wire 


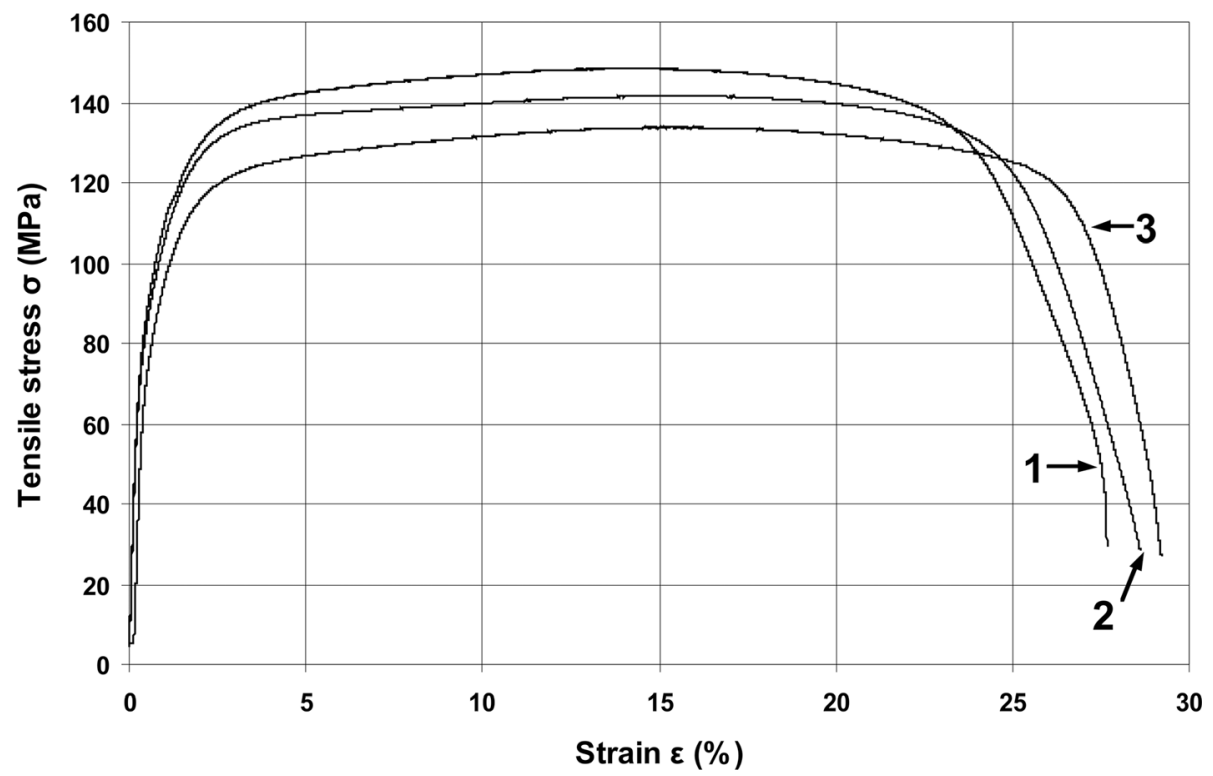

Fig. 4 Stress-strain curves for the KOBO extruded zinc with extrusion rate $0.5 \mathrm{~mm} / \mathrm{s}$, reverse die oscillation frequency $5 \mathrm{~Hz}$, extrusion force dropping from 1050 to $800 \mathrm{kN}$. Strain rate during tensile test $\dot{\varepsilon}=5 \times 10^{-4} \mathrm{~s}^{-1}$. Curve note is shown in Fig. 3

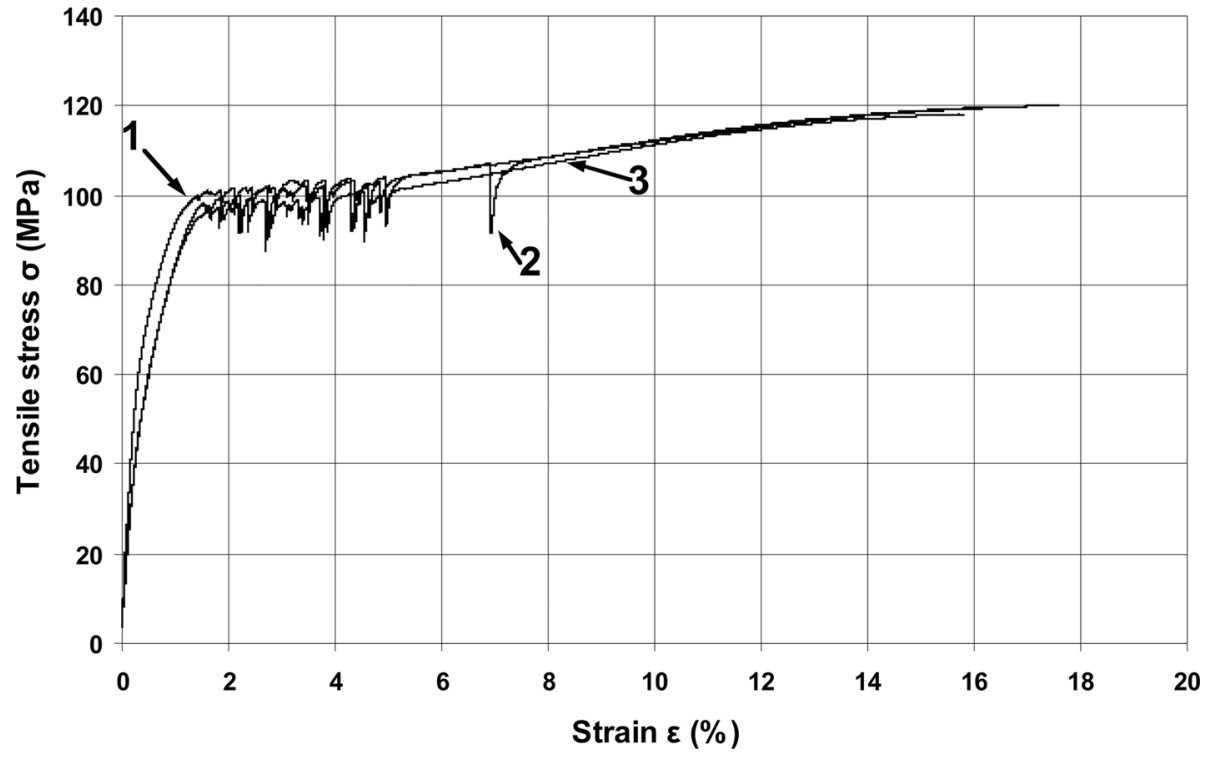

Fig. 5 Stress-strain curves for the KOBO extruded zinc with extrusion rate $0.1 \mathrm{~mm} / \mathrm{s}$, reduced reverse die oscillation frequency from 5 to 2 $\mathrm{Hz}$, extrusion force $600 \mathrm{kN}$. Strain rate during tensile test $\dot{\varepsilon}=3 \times 10^{-4} \mathrm{~s}^{-1}$. Curve note is shown in Fig. 3

through the die after a maximum extrusion force has been achieved. As shown in papers (Ref 7, 34), the drop in extrusion force occurring in the following stage of the KOBO procedure is neither dominated by the reduction of friction between the billet and inner walls of the press container, nor by the rise of temperature of the extruded metal, but by the intensifying increase in point defects concentration in the billet, which drastically reduces (by many levels of magnitude) the 'dynamic' viscosity coefficient. The torque value remains practically unchanged throughout the process (curve 3).

The decreasing extrusion force during the KOBO extrusion is responsible for the reduction of mechanical properties along the final product reaching several dozen percent (Ref 6, 7). Figure 3 and 4 shows two sets of stress-strain curves for zinc extruded by the KOBO method at two different speeds of the punch movement of 0.1 and $0.5 \mathrm{~mm} / \mathrm{s}$ while the other parameters remain the same. The sets are significantly different from one another in terms of stress-strain characteristics, flow stress levels and elongations. In the first case the stretched zinc clearly undergoes the Lüders effect, while in the second example the course of the tensile curve is monotonic (smooth, without strain surges, i.e., strain instability). The KOBO extrusion process at a lower speed requires the use of a force of 700 to $500 \mathrm{kN}$, while at higher speed the force range is between 1050 and $800 \mathrm{kN}$, which proves that the value of flow stress during tensile test depends on the level of extrusion force.

The registered differences in mechanical properties along the samples, obtained as a result of the KOBO extrusion, can be eliminated by introducing constant speed of the punch movement (constant strain rate $\dot{\varepsilon}$ ) and constant extrusion force (flow 


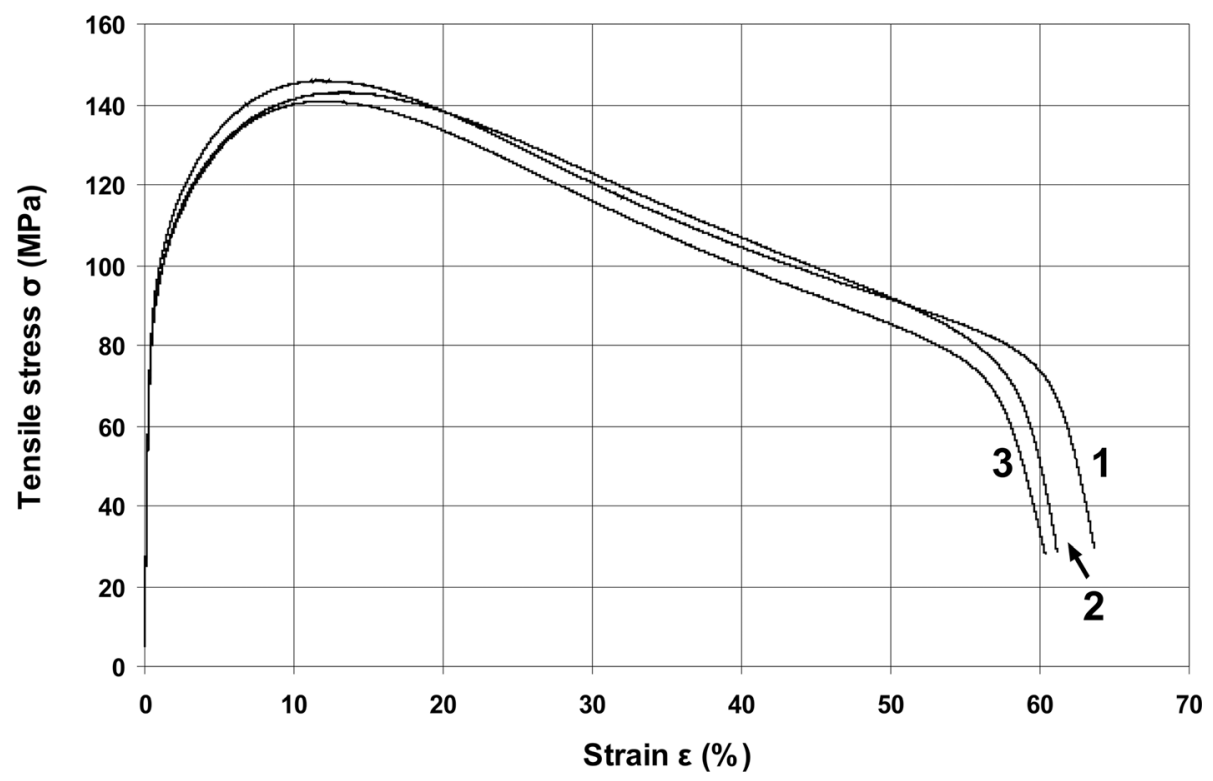

Fig. 6 Stress-strain curves for the KOBO extruded zinc with extrusion rate $0.5 \mathrm{~mm} / \mathrm{s}$, reduced reverse die oscillation frequency from 5 to 2 $\mathrm{Hz}$, extrusion force $900 \mathrm{kN}$. Strain rate during tensile test $\dot{\varepsilon}=7 \times 10^{-4} \mathrm{~s}^{-1}$. Curve note as shown in Fig. 3

stress $\sigma$ ), which is proved both, experimentally and theoretically with a Newtonian equation for metal flow $\sigma=\eta \dot{\varepsilon}$ (Ref 7, 32). Under such conditions, the value of the viscosity coefficient $\eta$ remains at its initial level during the whole extrusion process. As a result, the product has a uniformly homogeneous structure and identical mechanical properties throughout, regardless of the rising temperature of the billet during extrusion. As indicated in papers $(\operatorname{Ref} 7,32,33)$, the temperature of aluminum extruded at room temperature (20 ${ }^{\circ} \mathrm{C}$ ), in the final phase of the process exceeded $300{ }^{\circ} \mathrm{C}$ with absolutely no impact on its properties.

Also in zinc, extrusion at constant strain rate and extrusion force lead to constant mechanical properties throughout the whole wire. Results proving it true are presented in Fig. 5 for extrusion force of $600 \mathrm{kN}$ with a clearly visible Lüders effect and in Fig. 6, where a high level of extrusion force $(900 \mathrm{kN})$ results in a monotonic course of the stress-strain curves. In this case, maximum stress is reached after a short, initial period of elongation $(\sim 10 \%)$ accompanied by intense strengthening and followed by the creation of neck of the propagating type, which develops until the fracture of the sample at about $50 \%$ of elongation.

One of the main factors determining the level of extrusion force and therefore also the mechanical properties of the products obtained by the KOBO method is the extrusion rate. At constant twisting frequency, the applied extrusion force determines the number of oscillations per length unit and therefore decides about the level of extrusion force and the mechanical properties. The impact of extrusion speed on the mechanical properties of zinc is presented in Fig. 7. As indicated, during tensile tests carried out on products extruded at lower rate $(0.1$ and $0.33 \mathrm{~mm} / \mathrm{s})$, the Lüders phenomenon is initiated at a fairly low stress level. High extrusion rate $(0.5$ $\mathrm{mm} / \mathrm{s}$ ) on the other hand promotes monotonic characteristics.

The influence of constant die oscillation frequency (dropping extrusion force) on mechanical properties of zinc at constant extrusion rate is shown in Fig. 8, based on the tensile test. During the extrusion at constant frequencies of 3 and $5 \mathrm{~Hz}$, set speed of punch movement generates the same type of mechanical characteristics. The material strengthens within the range of a couple percent of elongation and then reaches a 'plateau,' which is followed by a decrease in stress linked to significant strain localization and the initiation of the neck. The stress-strain curve for a product obtained at the frequency of 8 $\mathrm{Hz}$ has a radically different shape and contains the Lüders-type deformation at a relatively low stress level. The differences of flow stress for the presented curves can be explained by the aforementioned fact that the higher frequency results in more twists per length unit and therefore the generation of more point defects per volume unit.

Further research on zinc KOBO extrusion has shown that the Lüders deformation can be linked to a particular level of extrusion force which depends on the die oscillation frequency. The higher the frequency, the lower the extrusion force. Graphs (in Fig. 9, 10,11) show the dependencies between the extrusion force and the mechanical characteristics of zinc at a constant speed punch movement value equal to $0.33 \mathrm{~mm} / \mathrm{s}$ and various die oscillation frequencies. The presented results suggest that in products obtained at lower die oscillation frequencies ( 3 and 5 $\mathrm{Hz}$ ) the extrusion force linked to the occurrence of Lüders deformation in zinc reaches a fairly low level of about $500 \mathrm{kN}$ (Fig. 9 and 10). Stress-strain curves obtained for zinc extruded at high die oscillation frequencies of $8 \mathrm{~Hz}$ (Fig. 11) are rather different. Zinc strengthens quickly and its plasticity is limited (the samples get destroyed at an elongation of about $15 \%$ ). It is also important to point out that during extrusion with the frequency of $8 \mathrm{~Hz}$ the Lüders phenomenon is observed in zinc at a relatively high extrusion force level of almost $900 \mathrm{kN}$.

The tensile tests conducted on zinc have shown significant differences in flow stress values depending on the applied tensile strain rate (Fig. 12 and 13). Under the Lüders effect conditions higher strain rate generates higher flow stress and reduces the range of the phenomenon (elongation). Unfortunately, mechanical instability means that it is pointless to mathematically determine the strain rate sensitivity $m$ and it is only possible to evaluate it 'optically.' In the case of initial 


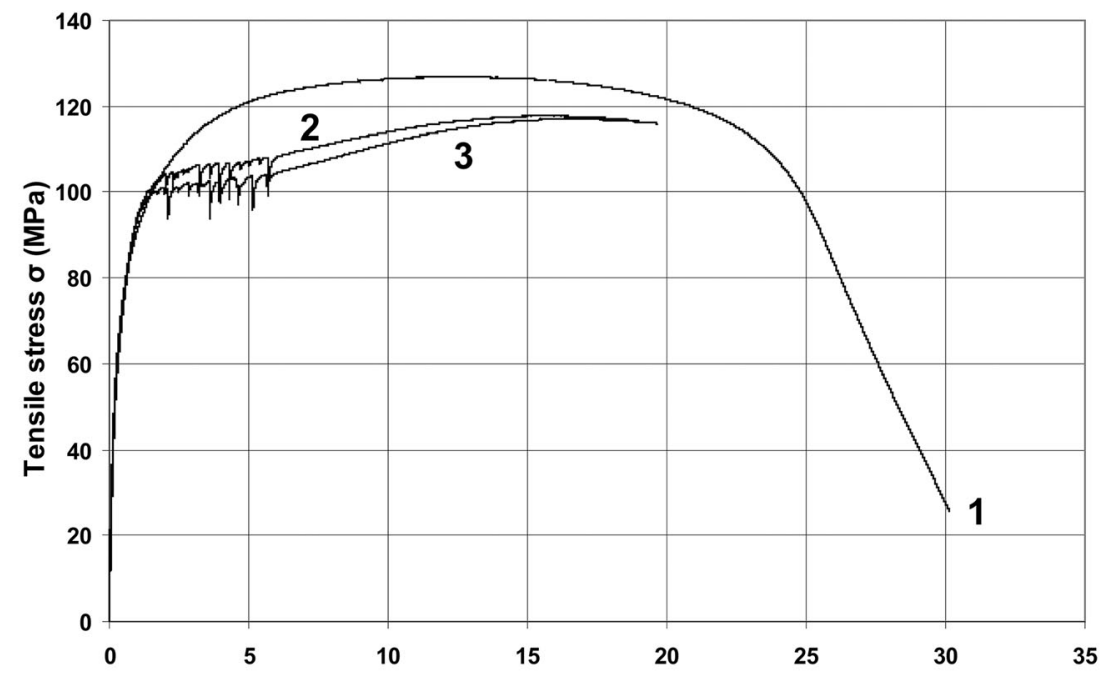

(a)

Strain $\varepsilon(\%)$

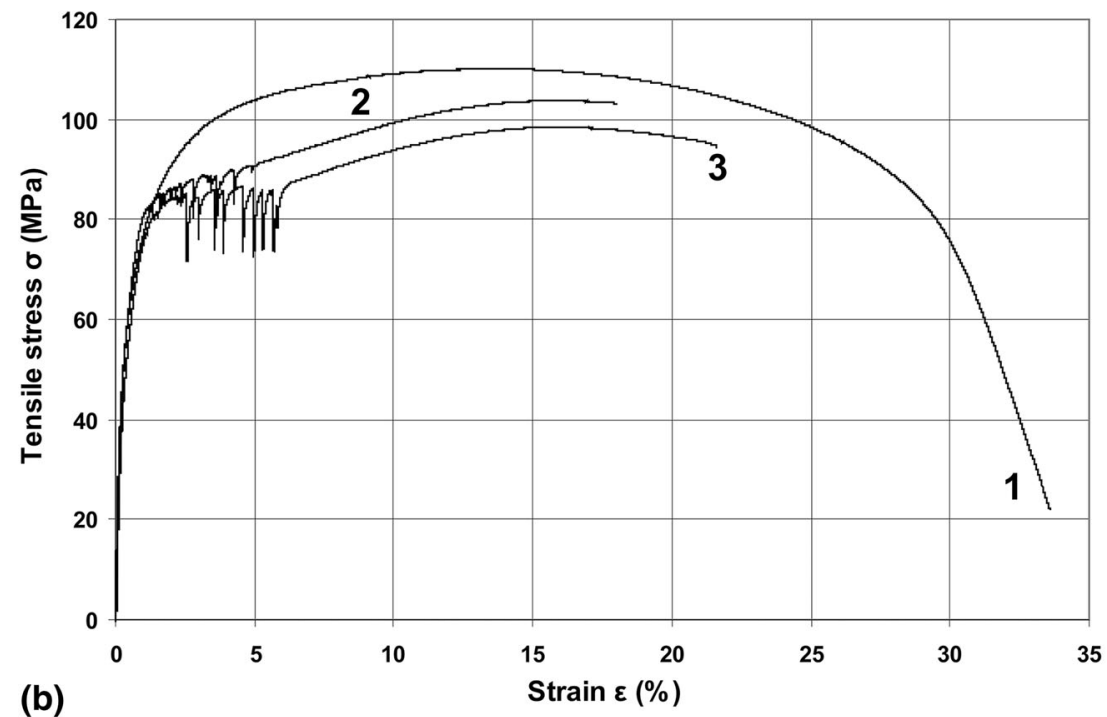

(b)

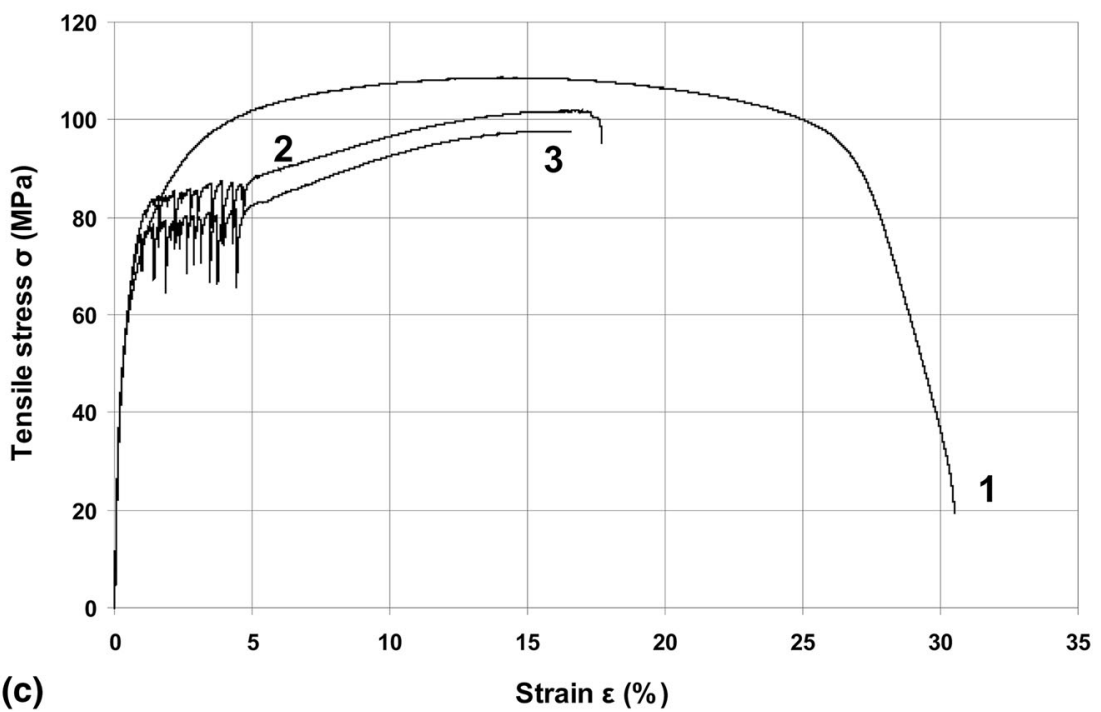

Fig 7 Impact of extrusion rate on stress-strain curves of the KOBO extruded zinc with extrusion rate $0.5 \mathrm{~mm} / \mathrm{s}(1) ; 0.33 \mathrm{~mm} / \mathrm{s}(2) ; 0.1 \mathrm{~mm} / \mathrm{s}$ (3), reverse die oscillation frequency $5 \mathrm{~Hz}$, extrusion force dropping from 800 to $600 \mathrm{kN}$. Strain rate during tensile test $\dot{\varepsilon}=1 \times 10^{-4} \mathrm{~s}^{-1}$. Samples taken from the beginning (a), middle (b) and end (c) sections of the wire 

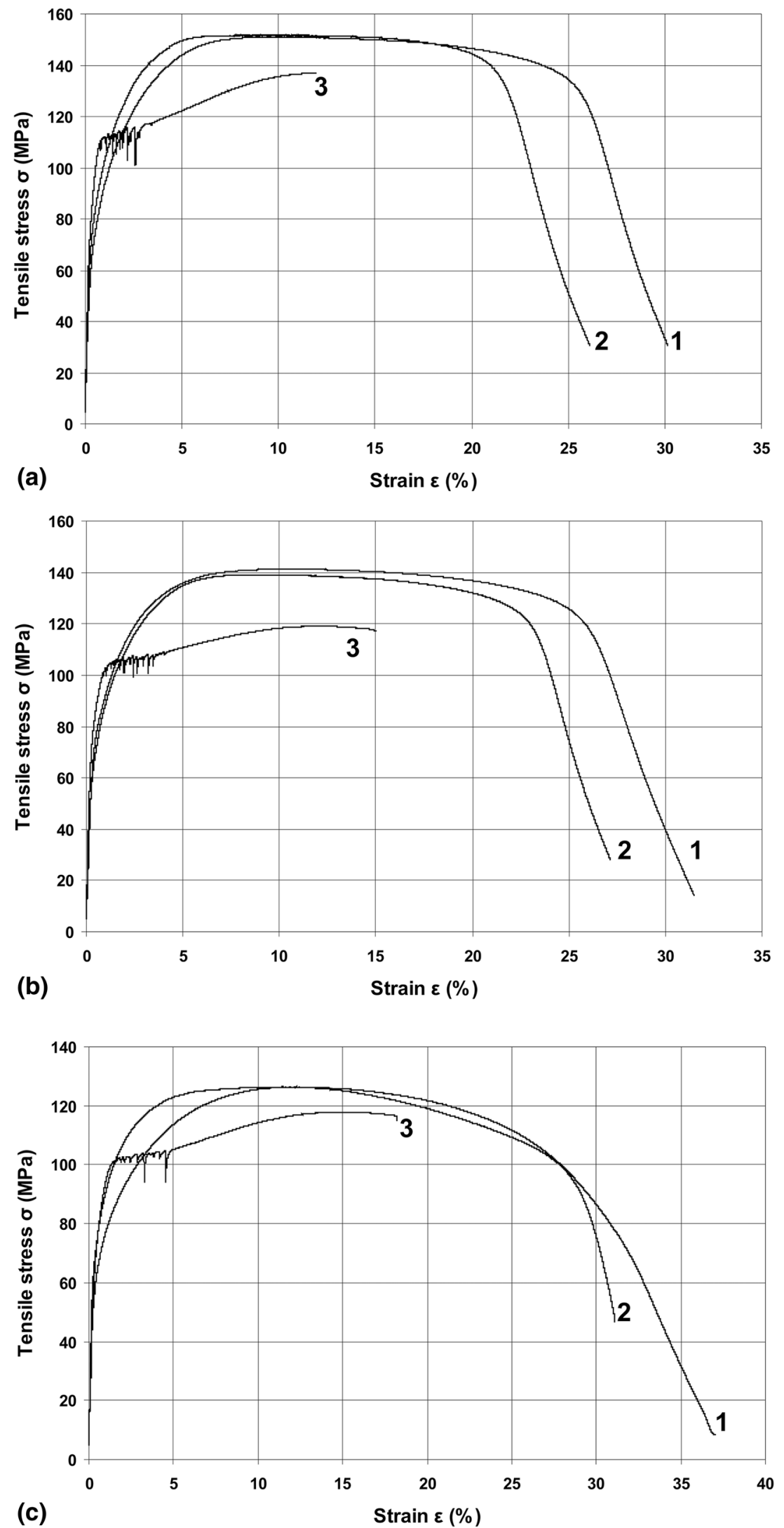

Fig. 8 Impact of reverse die oscillation frequency on stress-strain curves of the KOBO extruded zinc with extrusion rate $0.33 \mathrm{~mm} / \mathrm{s}$, reverse die oscillation frequency $3 \mathrm{~Hz}(1) ; 5 \mathrm{~Hz}(2) ; 8 \mathrm{~Hz}(3)$, extrusion force dropping from 900 to $700 \mathrm{kN}$. Strain rate during tensile test $\dot{\varepsilon}=5 \times 10^{-4}$ $\mathrm{s}^{-1}$. Samples taken from the beginning (a), middle (b) and end (c) sections of the wire 

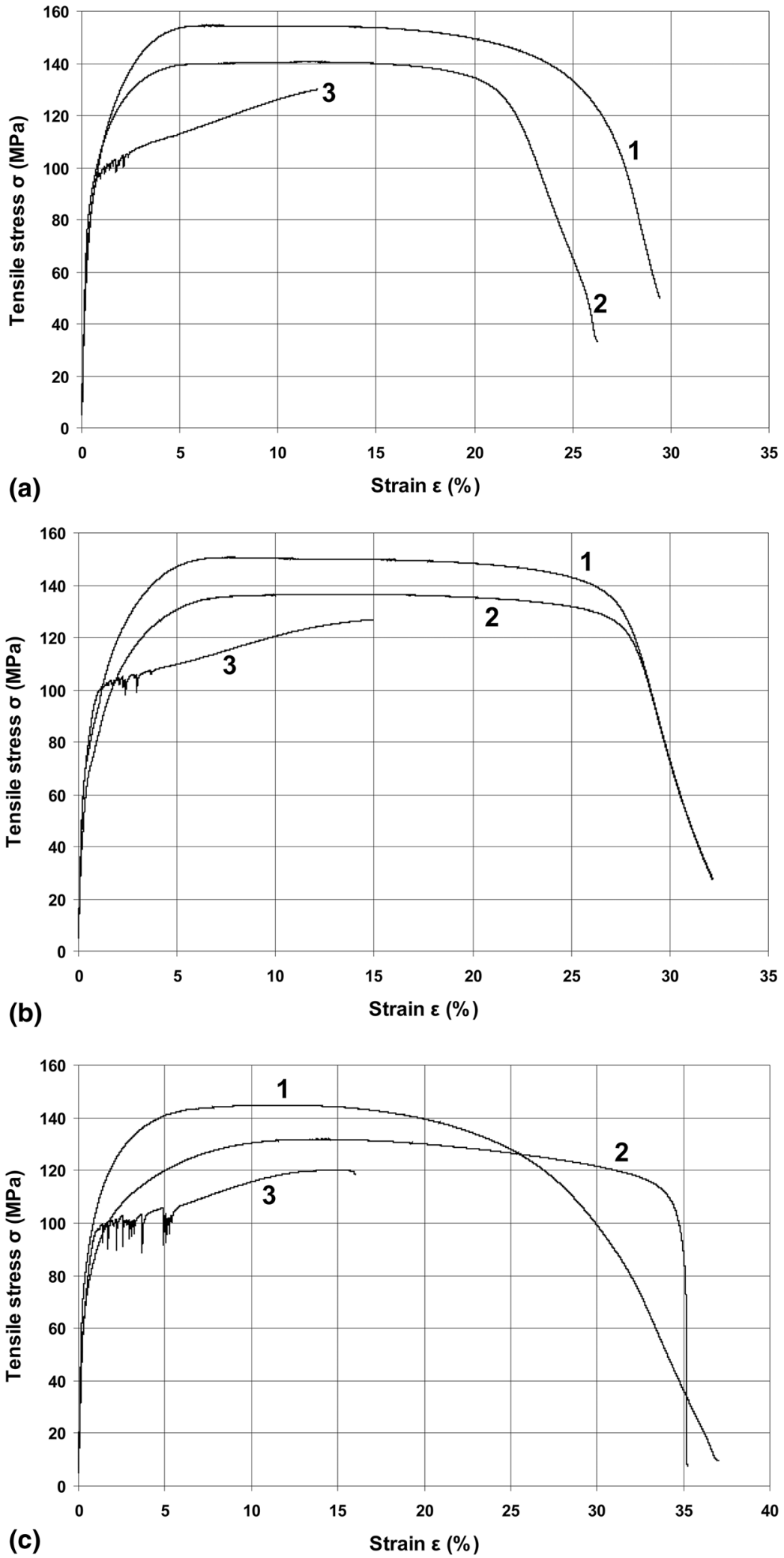

Fig. 9 Impact of extrusion force on stress-strain curves of the KOBO extruded zinc with extrusion rate $0.33 \mathrm{~mm} / \mathrm{s}$, reverse die oscillation frequency $3 \mathrm{~Hz}$, extrusion force dropping from: 1050 to $900 \mathrm{kN}$ (1); 850 to $700 \mathrm{kN} \mathrm{(2);600} \mathrm{to} 300 \mathrm{kN}$ (3). Strain rate during tensile test $\dot{\varepsilon}=$ $3 \times 10^{-4} \mathrm{~s}^{-1}$. Samples taken from the beginning (a), middle (b) and end (c) sections of the wire 

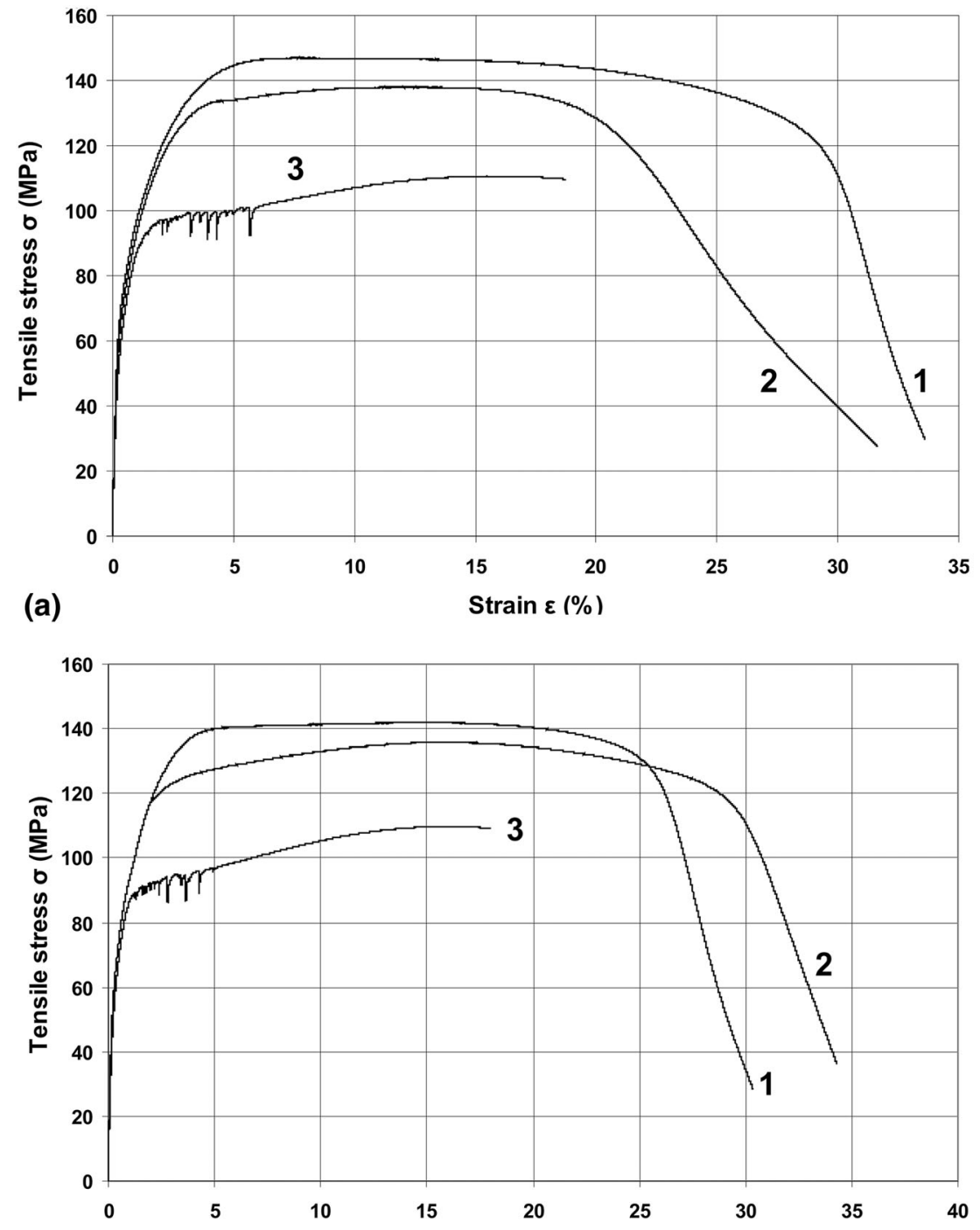

(b)

Strain $\varepsilon(\%)$

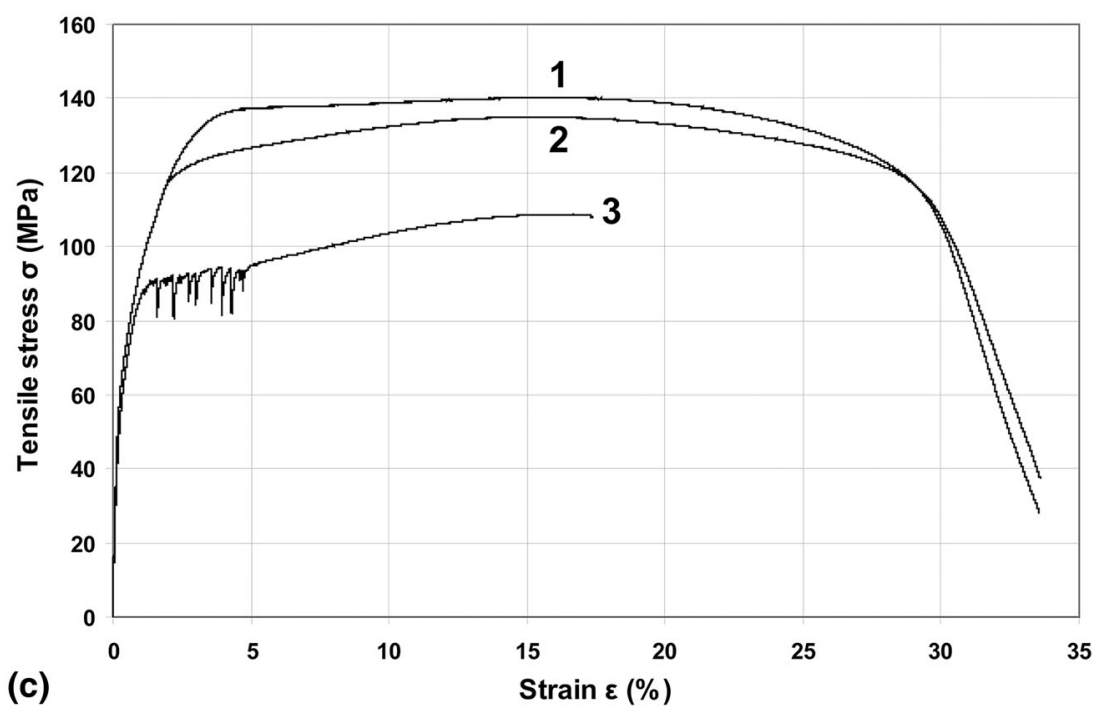

Fig. 10 Impact of extrusion force on stress-strain curves of the KOBO extruded zinc with extrusion rate $0.33 \mathrm{~mm} / \mathrm{s}$, reverse die oscillation frequency $5 \mathrm{~Hz}$, extrusion force dropping from: 1000 to $900 \mathrm{kN}(1) ; 900$ to $800 \mathrm{kN} \mathrm{(2);600} \mathrm{to} 300 \mathrm{kN}$ (3). Strain rate during tensile test $\dot{\varepsilon}=$ $3 \times 10^{-4} \mathrm{~s}^{-1}$. Samples taken from the beginning (a), middle (b) and end (c) sections of the wire 

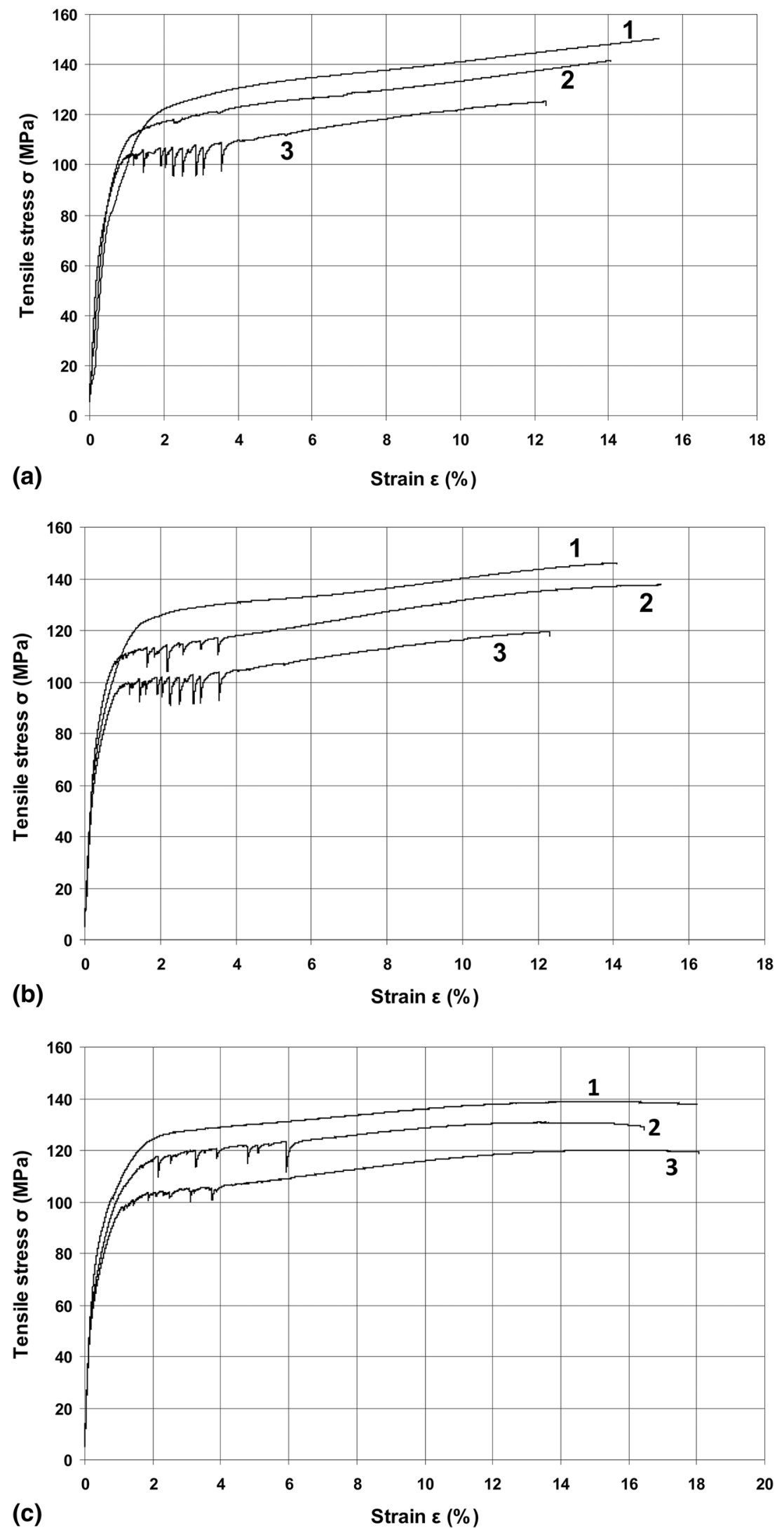

Fig. 11 Impact of extrusion force on stress-strain curves of the KOBO extruded zinc, extrusion rate $0.33 \mathrm{~mm} / \mathrm{s}$, reverse die oscillation frequency $8 \mathrm{~Hz}$, extrusion force dropping from: 1000 to $900 \mathrm{kN}$ (1); 900 to $700 \mathrm{kN}(2) ; 600$ to $300 \mathrm{kN}$ (3). Strain rate during tensile test $\dot{\varepsilon}=$ $7 \times 10^{-4} \mathrm{~s}^{-1}$. Samples taken from the beginning (a), middle (b) and end (c) sections of the wire 


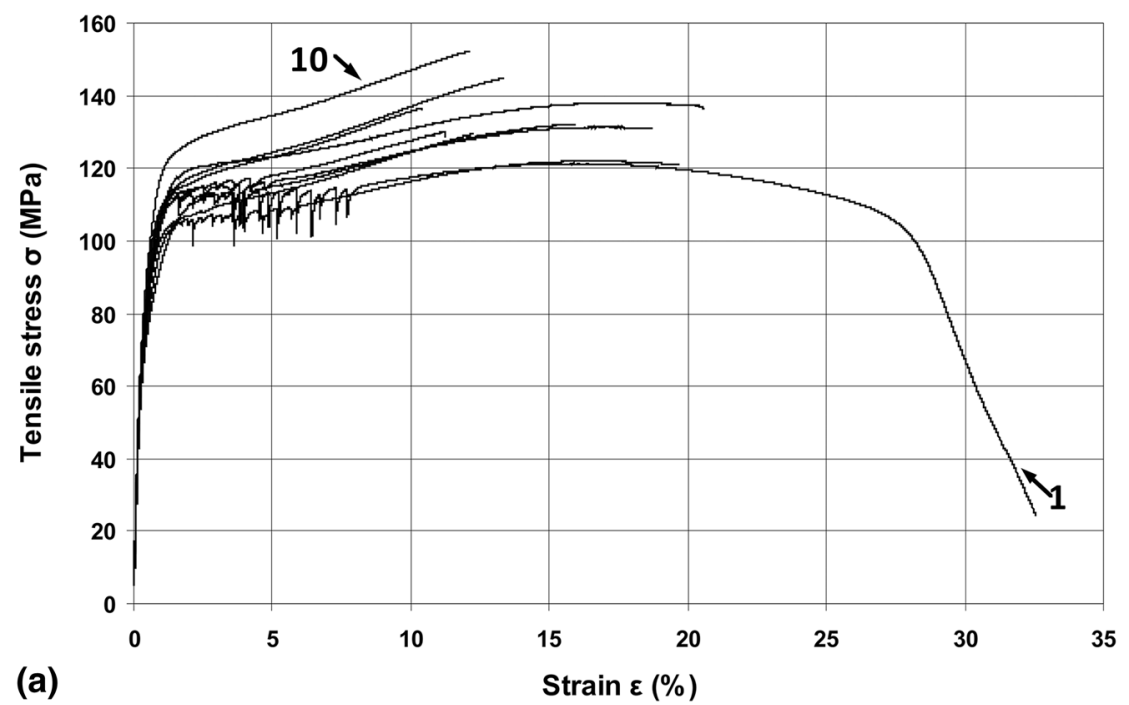

(a)

Strain $\varepsilon(\%)$

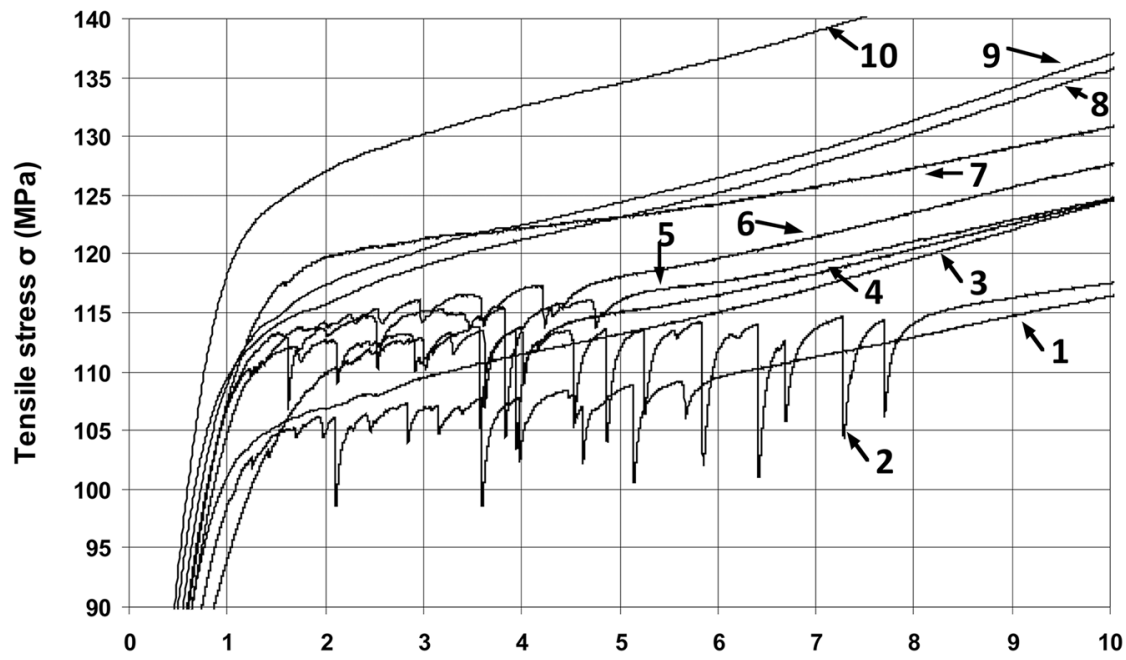

(b)

Strain $\varepsilon(\%)$

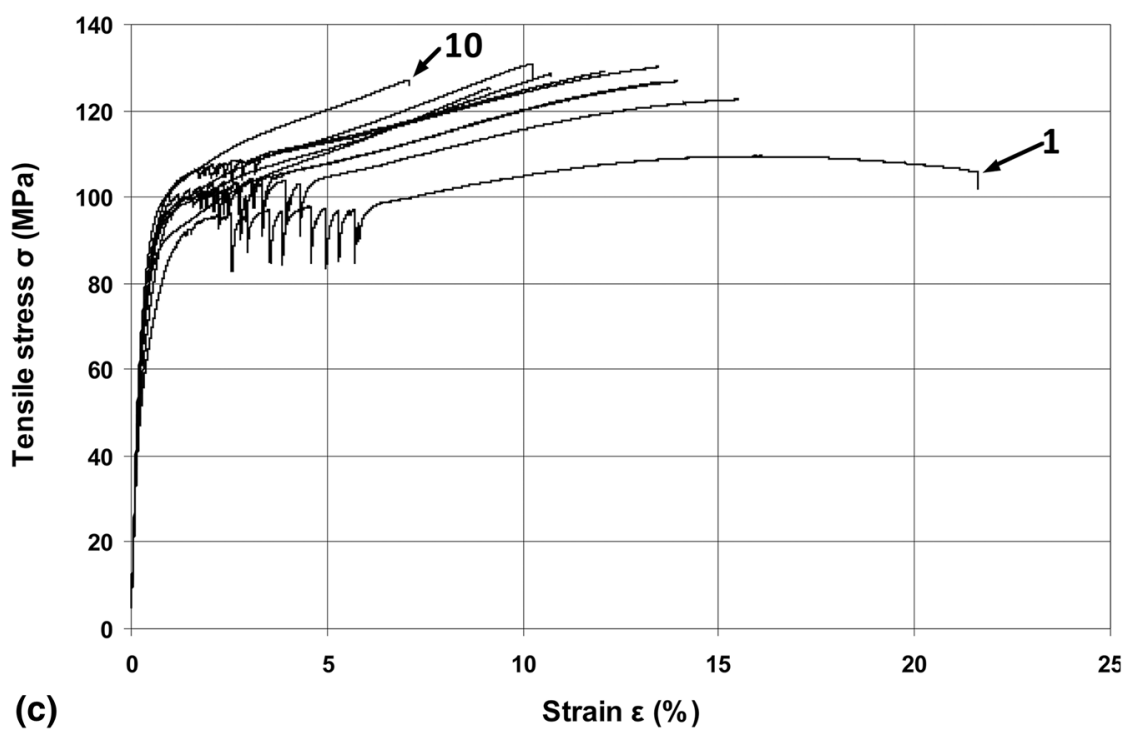

Fig. 12 Impact of strain rate on stress-strain curves of the $\mathrm{KOBO}$ extruded zinc with extrusion rate $0.5 \mathrm{~mm} / \mathrm{s}$, reverse die oscillation frequency $5 \mathrm{~Hz}$, extrusion force dropping from 600 to $400 \mathrm{kN}$. Samples taken from the beginning (a,b), middle (c,d) and end (e,f) sections of the wire. Extensions of the non-homogenous range of deformation (b,d,f). Strain rate during tensile test $\dot{\varepsilon}: 1 \times 10^{-4} \mathrm{~s}^{-1}(1) ; 3 \times 10^{-4} \mathrm{~s}^{-1}(2) ; 5 \times 10^{-4} \mathrm{~s}^{-1}$ (3); $7 \times 10^{-4} \mathrm{~s}^{-1}(4) ; 9 \times 10^{-4} \mathrm{~s}^{-1}(5) ; 1 \times 10^{-3} \mathrm{~s}^{-1}(6) ; 3 \times 10^{-3} \mathrm{~s}^{-1}(7) ; 5 \times 10^{-3} \mathrm{~s}^{-1}(8) ; 7 \times 10^{-3} \mathrm{~s}^{-1}(9) ; 9 \times 10^{-3} \mathrm{~s}^{-1}(10)$ 


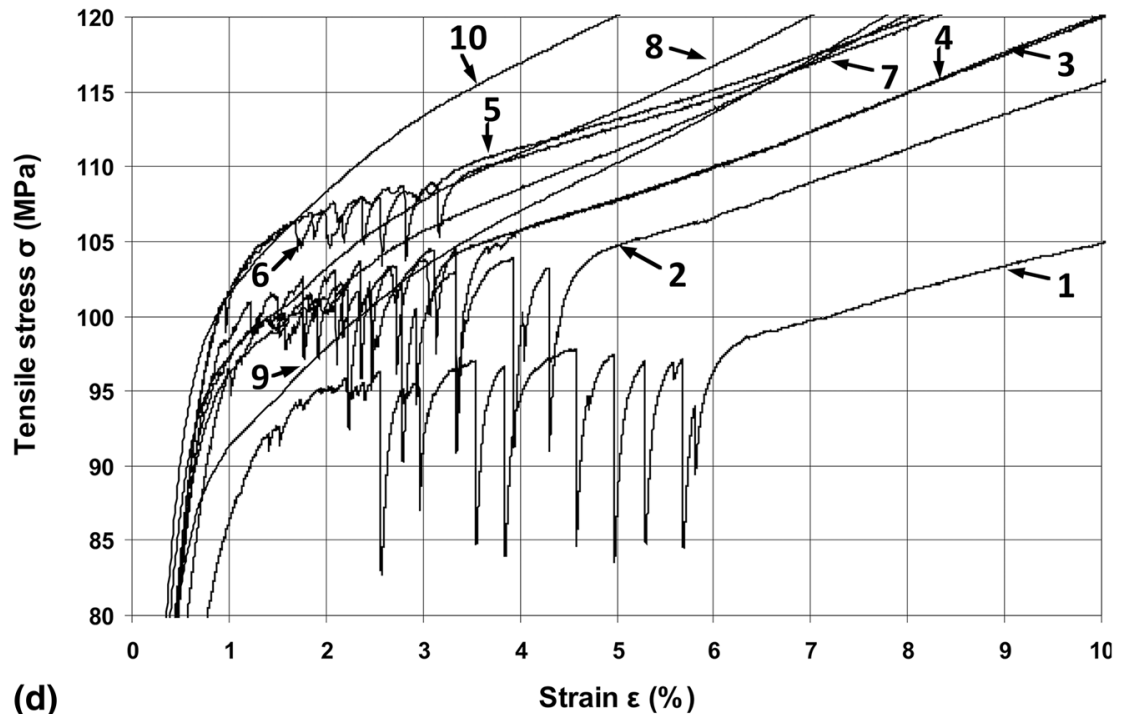

(d)

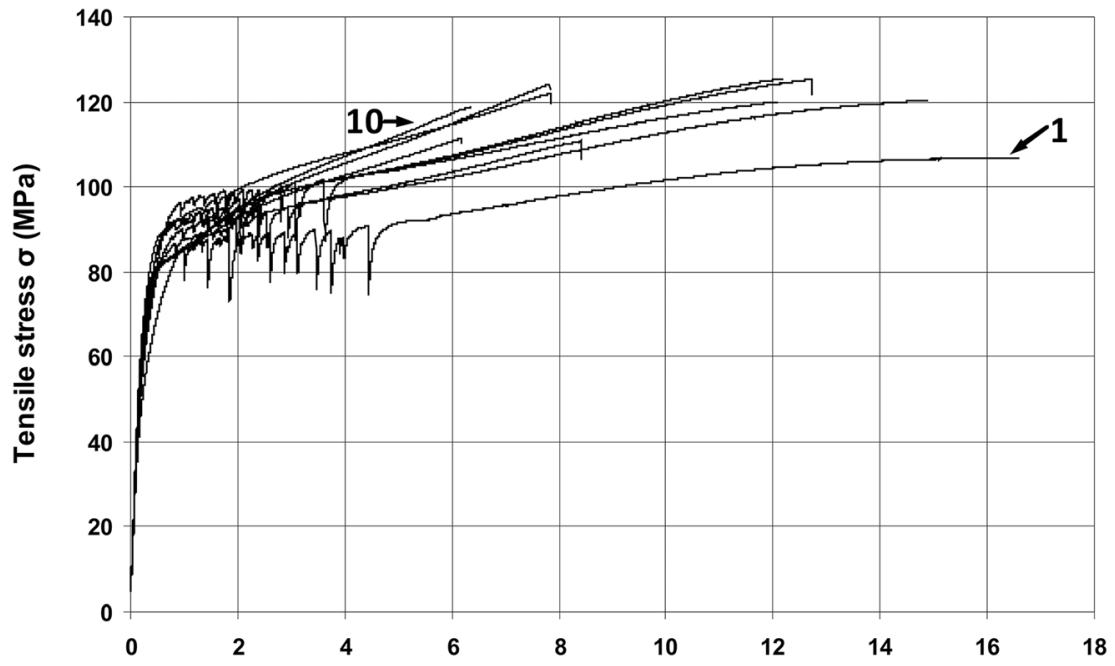

(e)

Strain $\varepsilon(\%)$

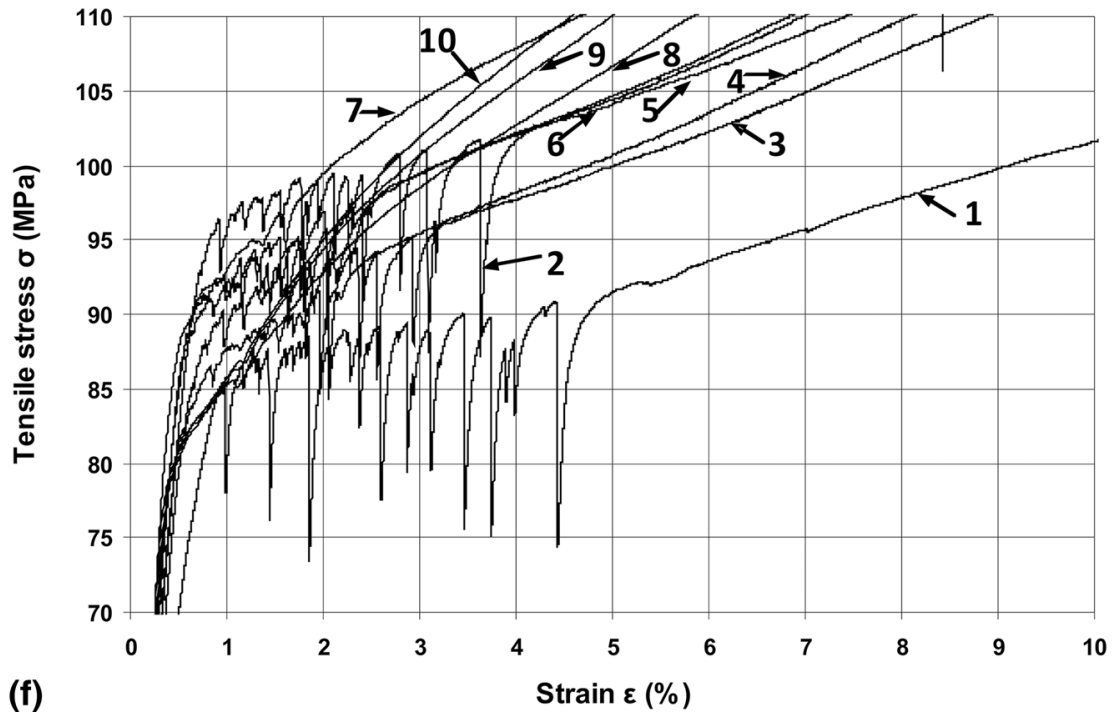

Fig. 12 continued 

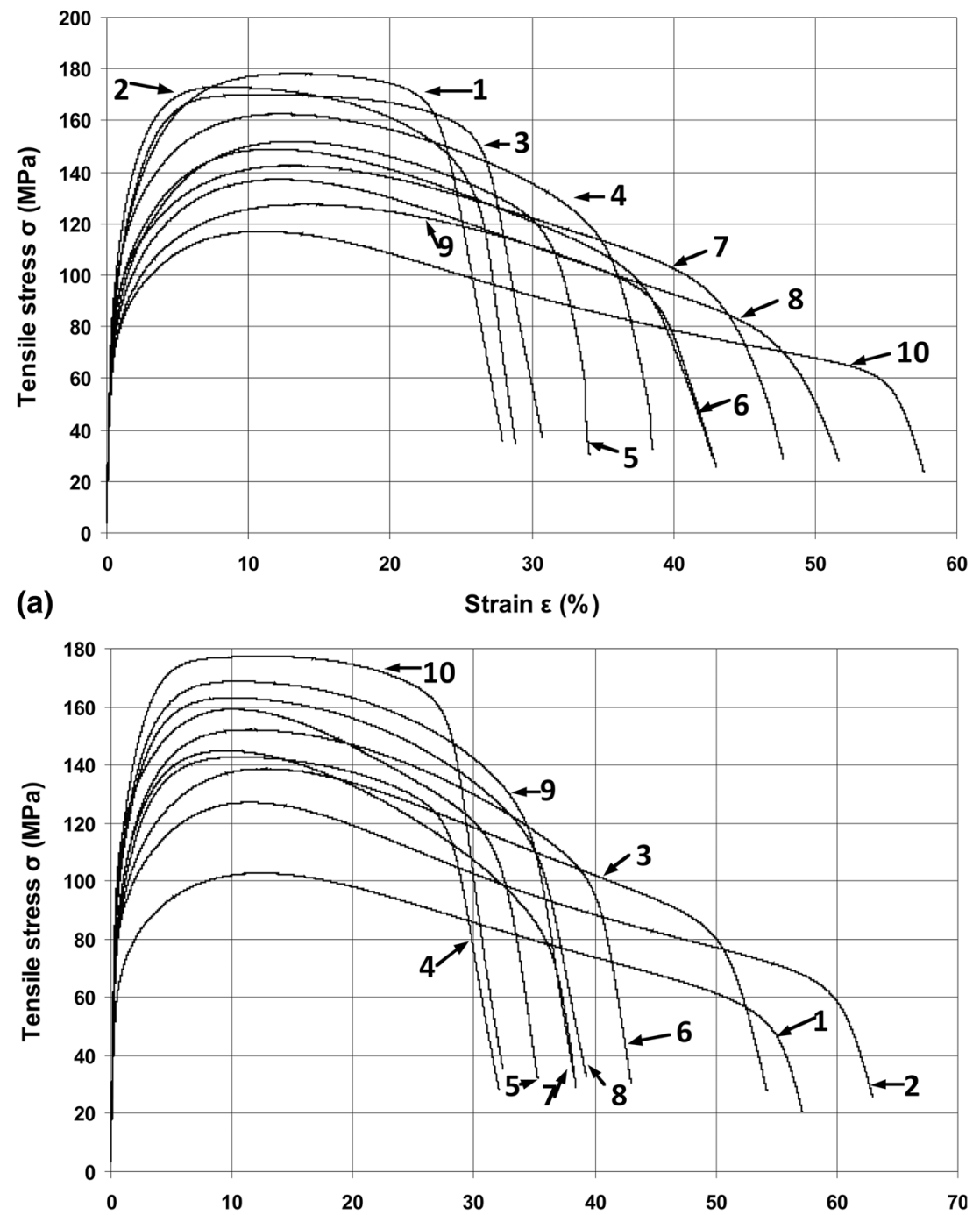

(b)

Strain $\varepsilon(\%)$

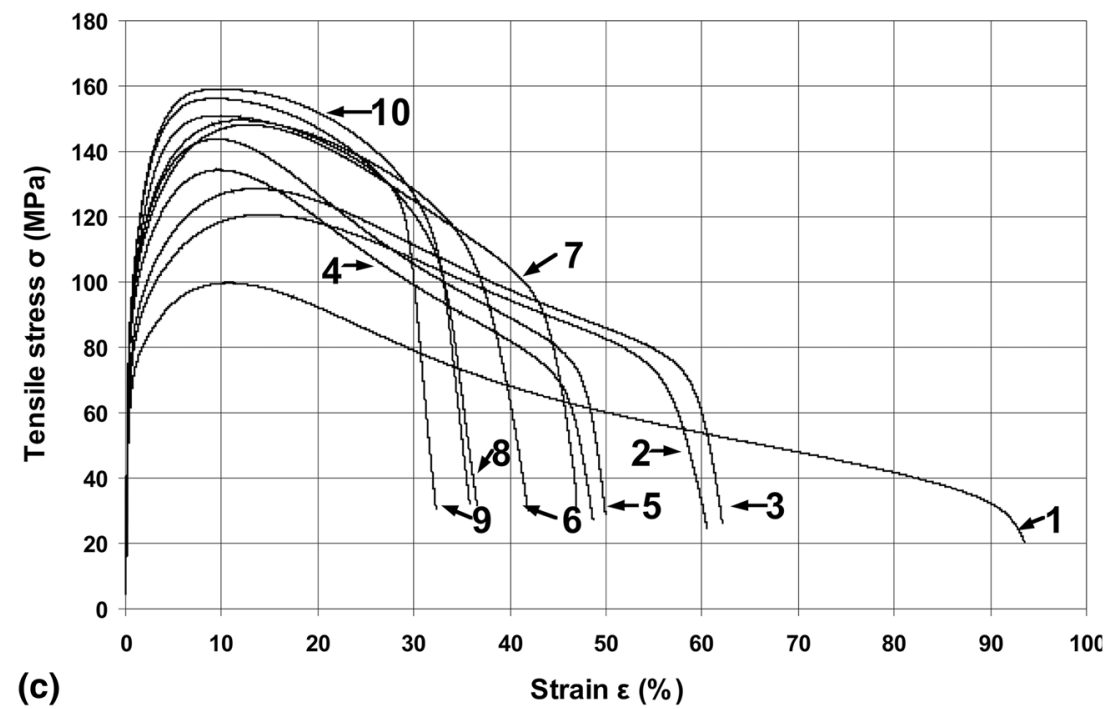

Fig. 13 Stress-strain curves of the KOBO extruded zinc with extrusion rate $0.5 \mathrm{~mm} / \mathrm{s}$, reverse die oscillation frequency $5 \mathrm{~Hz}$, extrusion force dropping from 1050 to $800 \mathrm{kN}$. Samples taken from the beginning (a), middle (b) and end (c) sections of the wire. Curve note is shown in Fig. 12 


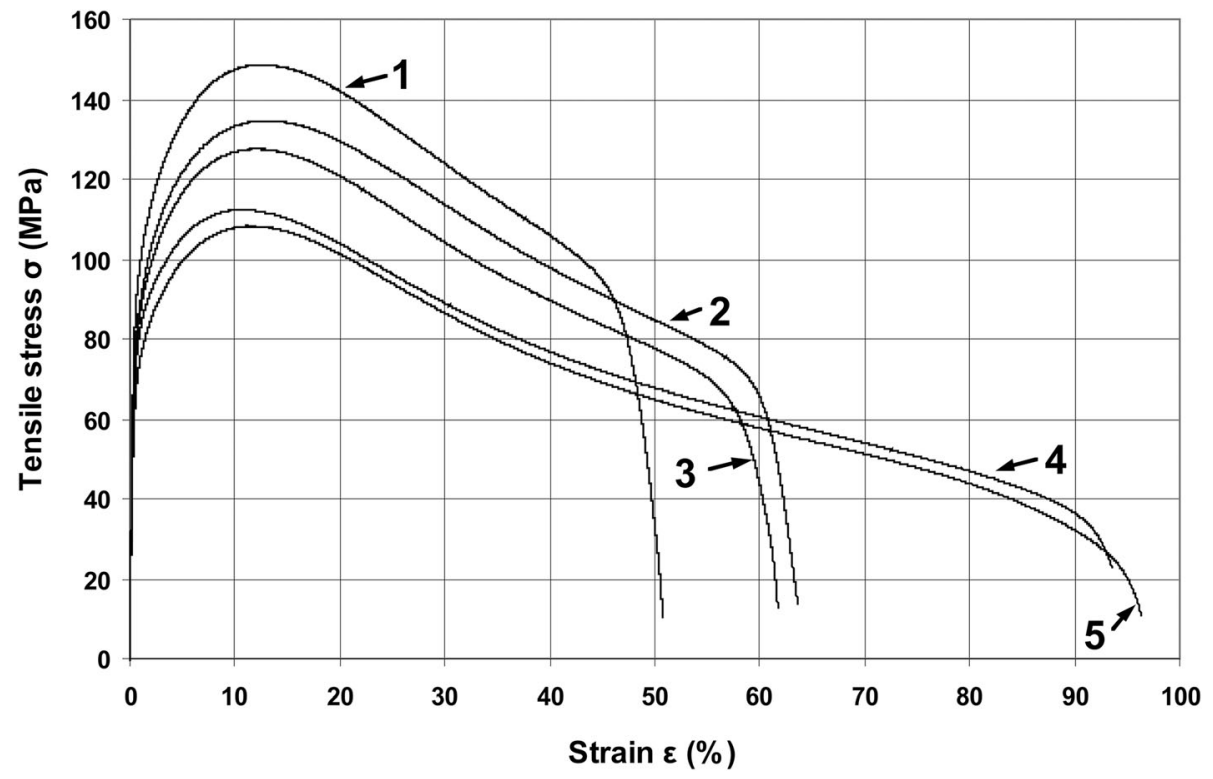

Fig. 14 Impact of strain rate on stress-strain curves of the KOBO extruded zinc with extrusion rate $0.1 \mathrm{~mm} / \mathrm{s}$, reverse die oscillation frequency $3 \mathrm{~Hz}$, extrusion force dropping from 850 to $700 \mathrm{kN}$. Samples taken from the end section of the rod. Strain rate during tensile test $\dot{\varepsilon}: 9 \times 10^{-4} \mathrm{~s}^{-1}$ (1); $7 \times 10^{-4} \mathrm{~s}^{-1}(2) ; 5 \times 10^{-4} \mathrm{~s}^{-1}(3) ; 3 \times 10^{-4} \mathrm{~s}^{-1}(4) ; 1 \times 10^{-4} \mathrm{~s}^{-1}(5)$

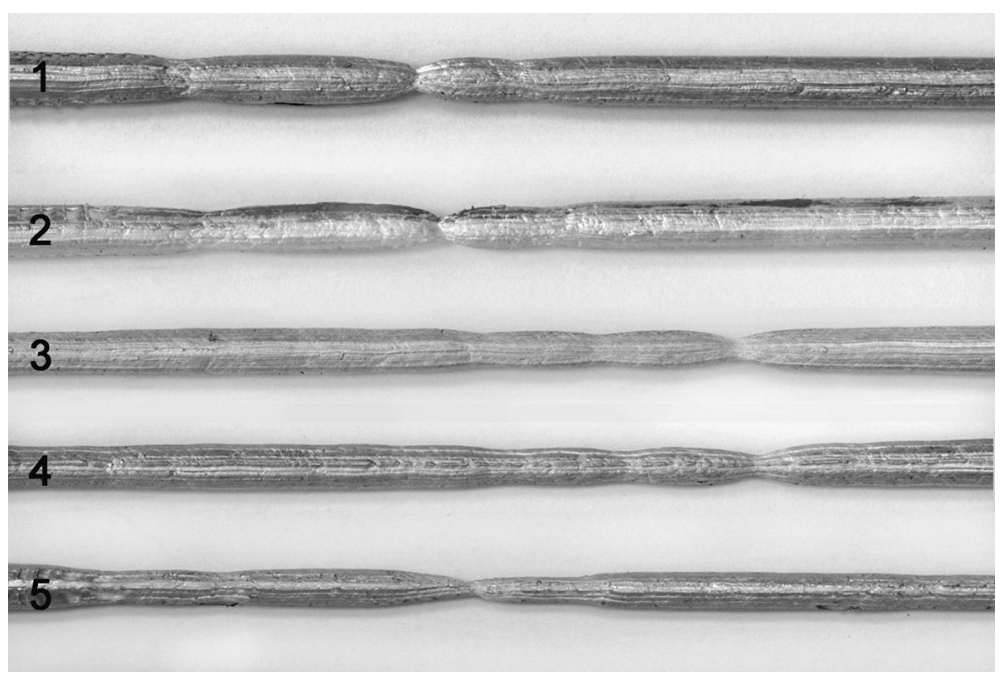

Fig. 15 Images of zinc samples extruded by the KOBO method and subjected to tensile testing with parameters as shown in Fig. 14

largely homogeneous stress-strain curves for zinc, it is otherwise. Average values of this parameter given by the Eq 1 for zinc extruded at the rate of $0.5 \mathrm{~mm} / \mathrm{s}$ and die oscillation frequency of $5 \mathrm{~Hz}$ equal 0.112 (for samples taken from the beginning), 0.138 (from the middle) and 0.115 (from the end part of the wire). Such high strain rate sensitivity at room temperature suggests that during the KOBO process zinc acquires properties predisposing it to superplastic-type flow. To compare, this parameter for pure zinc with a grain size of 40 $\mu \mathrm{m}$ extruded conventionally is on average 0.078 and that for zinc with a grain size of $300 \mu \mathrm{m}$ equals 0.068 (Ref 30 ).

Some of the zinc samples extruded by the KOBO method have a tendency to form multiple necks during tensile testing. Stress-strain curves for the samples with localization of deformation (neck), its fixing and continuation of plastic flow taking place in a different part of the sample are all shown in Fig. 14, while the images of the samples are presented in Fig. 15. Stress-strain curves after obtaining maximum values of stress (at an elongation of around 10\%) are still monotonic up to an elongation of about $90 \%$. This paper only documents this phenomenon without attempting to explain it.

\subsection{Structural Research}

The commonly held view that the Lüders deformation is strongly linked to intensely fragmented grains was verified by studies on samples extruded by the KOBO method at a constant extrusion rate and extrusion force. Mechanical characteristics of samples that enabled to determine grain sizes for zinc exhibiting Lüders phenomenon are presented in Fig. 16. Grain 


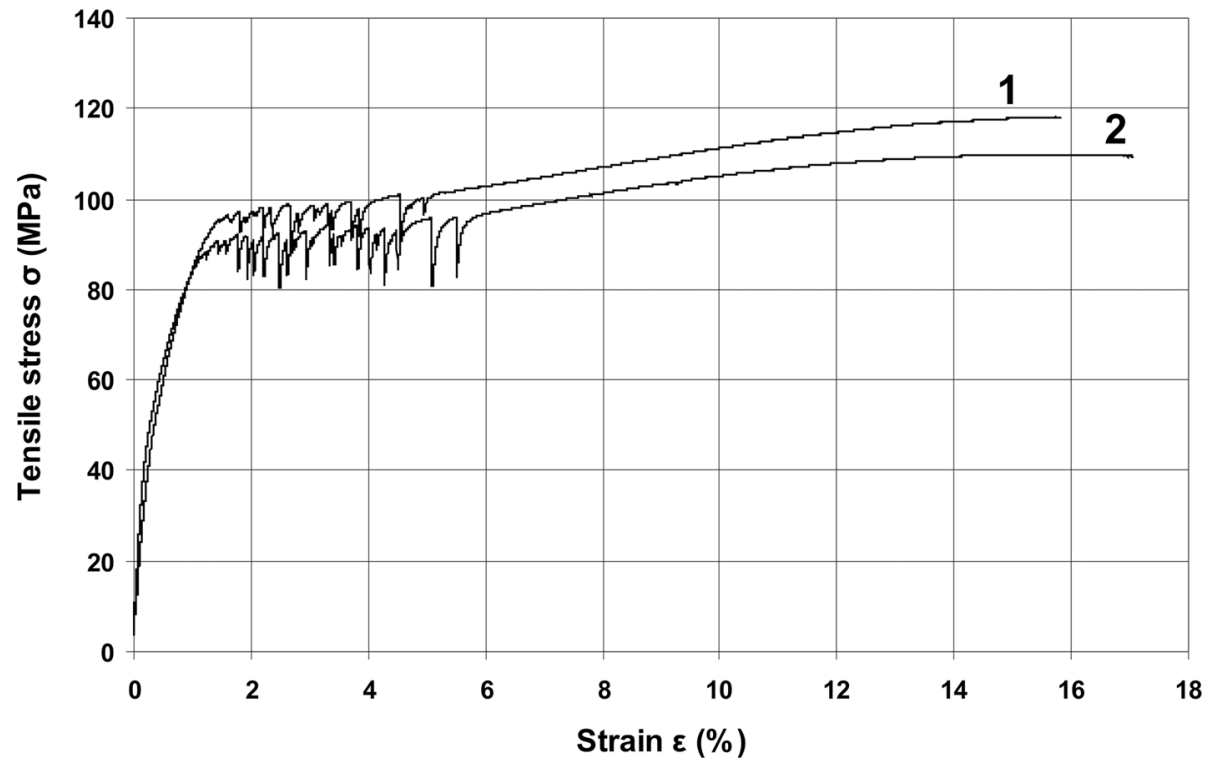

Fig. 16 Stress-strain curves for the KOBO extruded zinc exhibiting non-homogeneous Lüders-type deformation. Extrusion rate $0.5 \mathrm{~mm} / \mathrm{s}$, reverse die oscillation frequency reduced from 5 to $3 \mathrm{~Hz}$, extrusion force $400 \mathrm{kN}$. Strain rate during tensile test $\dot{\varepsilon}=3 \times 10^{-4} \mathrm{~s}{ }^{-1}$. Samples taken from the beginning (1) and end (2) of the wire
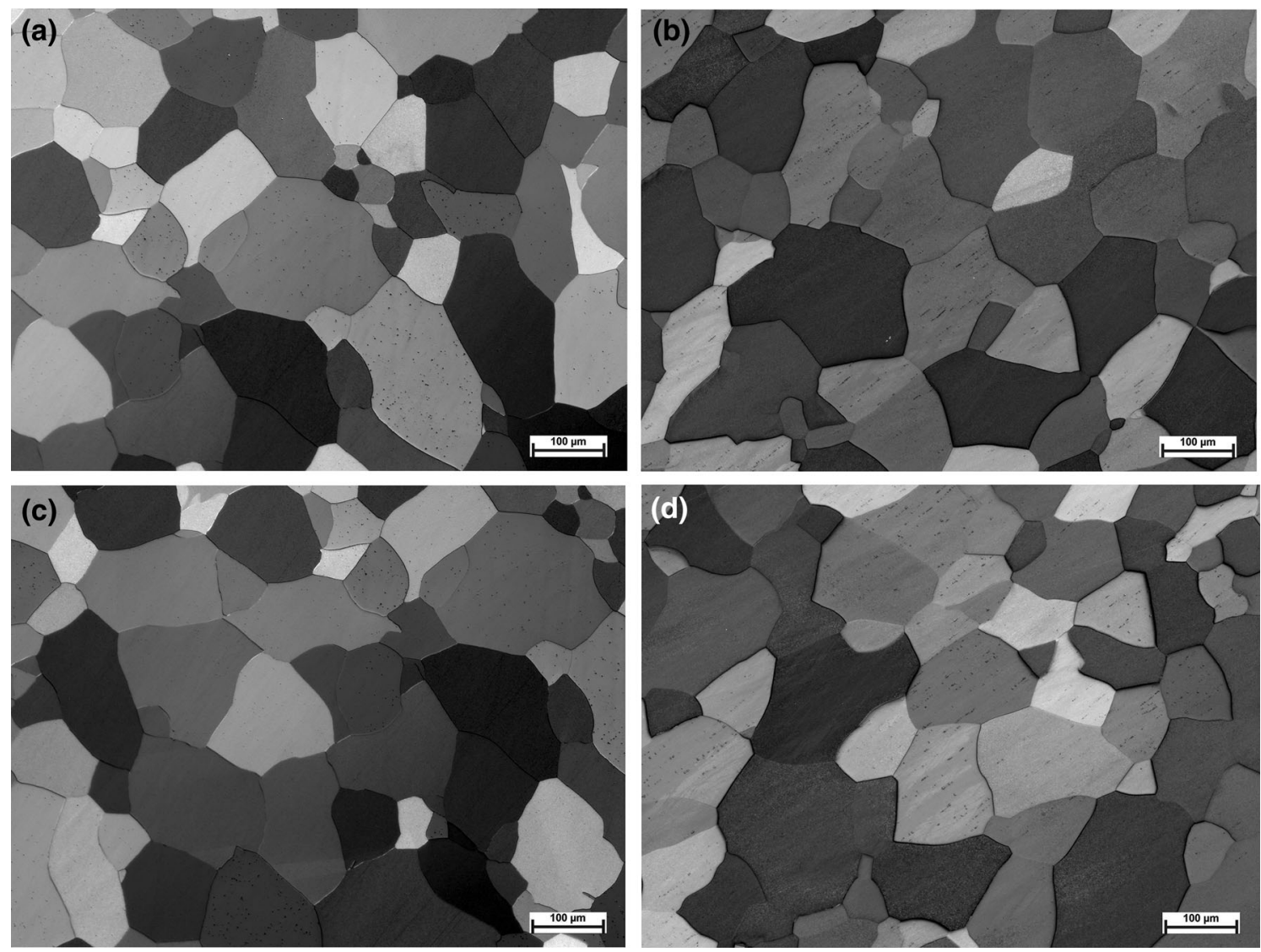

Fig. 17 Microstructures of zinc samples with mechanical characteristics (tensile tests) as shown in Fig. 16, observed in transverse (a,c) and longitudinal $(b, d)$ cross sections from the beginning $(a, b)$ and end parts of the wire $(c, d)$ 
sizes are the same throughout the sample and equal around 100 $\mu \mathrm{m}$. According to earlier research results published in paper (Ref 31), Lüders effect was also observed in zinc with a grain size of 10-25 $\mu \mathrm{m}$, although the phenomenon was extending its range (elongation) along with the reduction in grain size and extrusion rate.

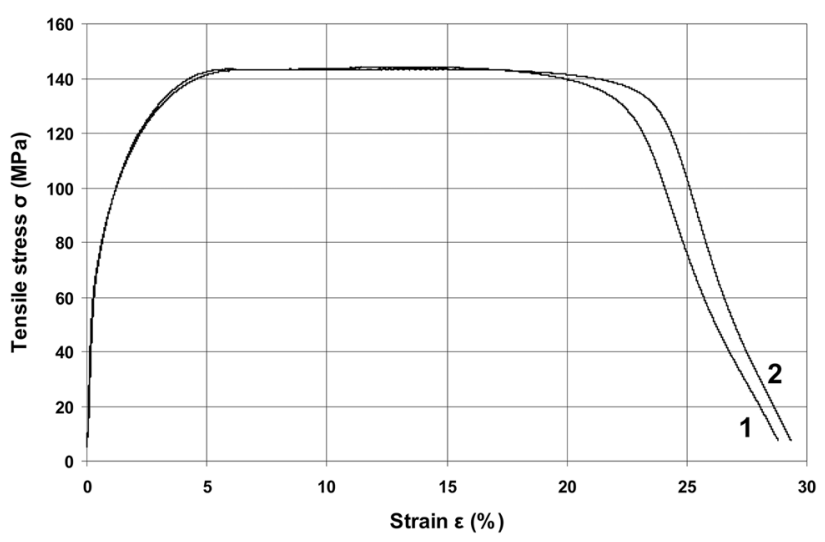

Fig. 18 Stress-strain curves for the KOBO extruded zinc exhibiting homogeneous deformation. Extrusion rate $0.5 \mathrm{~mm} / \mathrm{s}$, reverse die oscillation frequency reduced from 5 to $3 \mathrm{~Hz}$, extrusion force 800 $\mathrm{kN}$. Strain rate during tensile test $\dot{\varepsilon}=8 \times 10^{-4} \mathrm{~s}^{-1}$. Curve note as shown in Fig. 16
Grain sizes for KOBO extruded zinc exhibiting monotonic stress-strain curves were also measured. In this case, samples extruded at the rate of $0.5 \mathrm{~mm} / \mathrm{s}$ and frequency dropping from 5 to $3 \mathrm{~Hz}$ at the extrusion force $(800 \mathrm{kN})$ in comparison with the material exhibiting Lüders phenomenon (as shown in Fig. 17) were examined. Such process conditions made it possible to obtain a product that was homogeneous throughout the sample. Its characteristics are presented in Fig. 18, while its structure is shown in Fig. 19.

Grain fragmentation is widely considered to be the cause of Lüders phenomenon; however, it was not found to be true during the research of the KOBO extruded zinc samples. Lüders phenomenon is observed in materials with size grains of about $100 \mu \mathrm{m}$ and does not occur in samples with grain sizes of about $30 \mu \mathrm{m}$ exhibiting a monotonic course of the $\sigma-\varepsilon$ dependency.

Electron microscopy observations of zinc samples extruded by the KOBO method at the rate of $0.5 \mathrm{~mm} / \mathrm{s}$ and constant frequency of $5 \mathrm{~Hz}$ showing non-homogeneous Lüders deformation (as shown in Fig. 16) were made under the conditions of relevant diffraction contrast. They revealed the presence of 'strips' (Fig. 20), similar to those first mentioned in paper (Ref 34). During the observations (radiation with an electron beam), these 'strips' get smudged (Fig. 21) and evolve into rows of socalled black spots or, in other words, clusters (Ref 6, 32, 34, 35). Areas in the form of strips dotted with clusters have transcrystalline positions and can be identified as shear bands. A rather different structure (Fig. 22) was revealed in samples
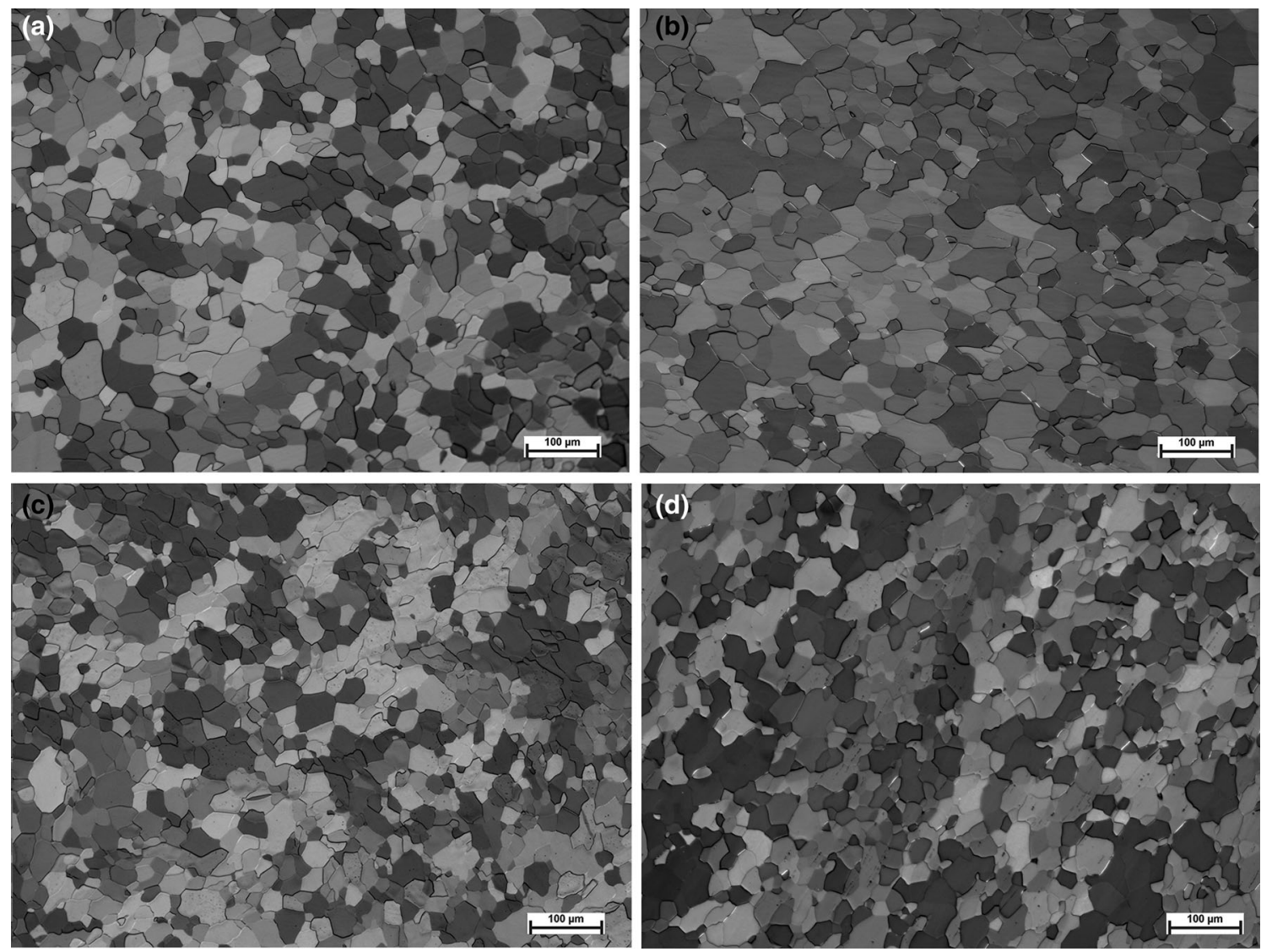

Fig. 19 Microstructures of samples as shown in Fig. 18 observed in transverse $(a, c)$ and longitudinal (b,d) cross sections from the beginning $(a, b)$ and end parts of the wire $(c, d)$ 

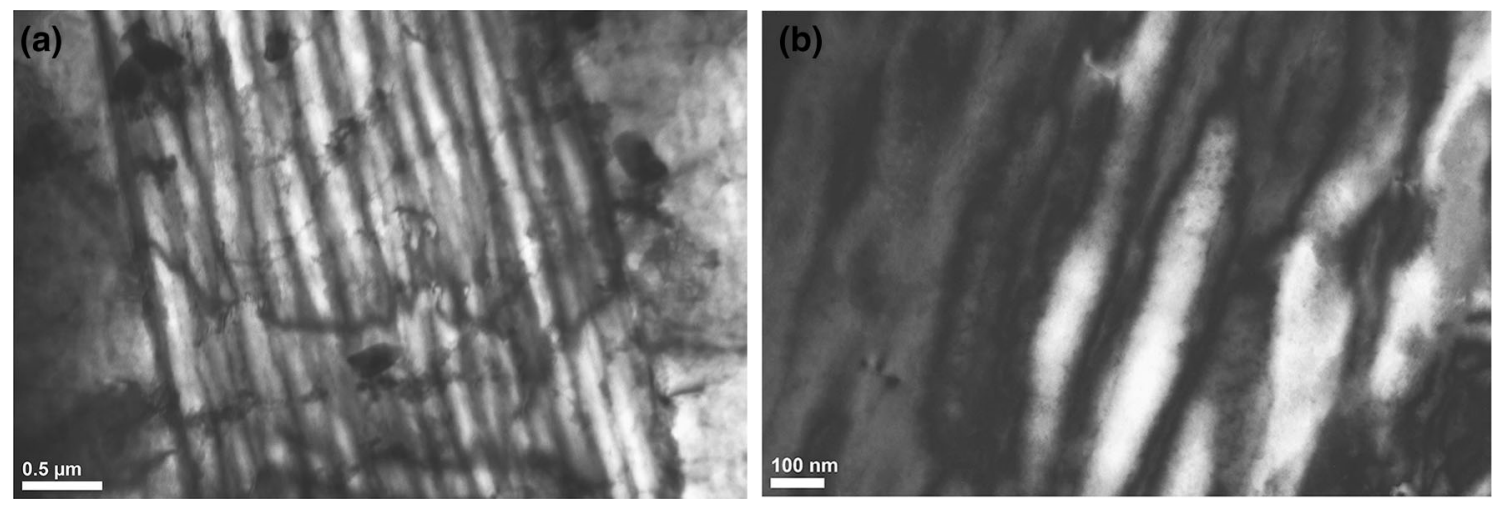

Fig. 20 Microstructure of the KOBO extruded zinc samples exhibiting Lüders deformation (as shown in Fig. 16); (a,b) different magnifications
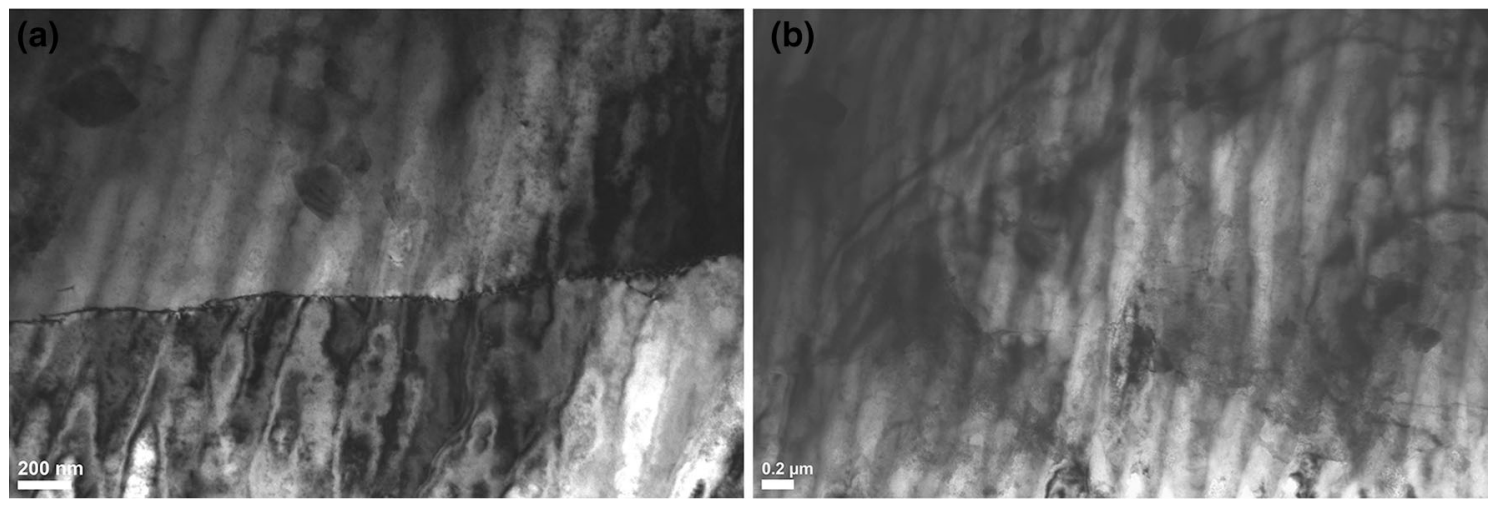

Fig. 21 'Strips' smudged after being heated by a beam of electrons (TEM) in a sample exhibiting Lüders deformation (as shown in Fig. 16); $(\mathrm{a}, \mathrm{b})$ different magnifications

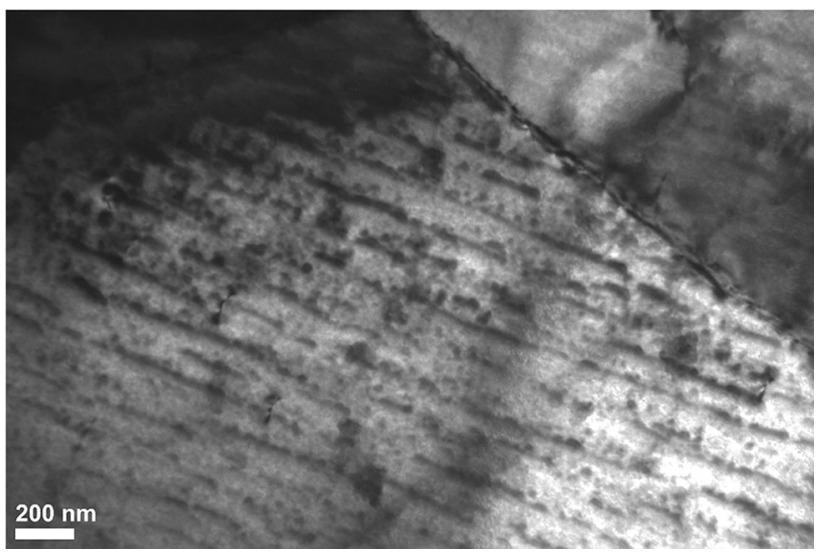

Fig. 22 Rows of point defects in the form of clusters in zinc extruded by the KOBO method at the extrusion force of $800 \mathrm{kN}$ (monotonic stress-strain curve as shown in Fig. 18)

exhibiting a homogeneous course of deformation (as shown in Fig. 18) extruded by the KOBO method at the rate of $0.5 \mathrm{~mm} / \mathrm{s}$ and constant extrusion force of $800 \mathrm{kN}$, which was maintained by systematic decrease in frequency from 5 to $3 \mathrm{~Hz}$. Its microstructure shows the stage when the 'strips' (shear bands) highly saturated with point defects are transformed into rows of clusters, the size of which is estimated to be around $2 \mathrm{~nm}$. The presence of over-equilibrial concentration of point defects and their evolution into rows of clusters determine the mechanical properties of zinc. Unlike in monotonic stress-strain curves with the domination of well-formed clusters, shear bands (strips) over-saturated with point defects are responsible for the occurrence of Lüders effect.

Data on the Lüders-type deformation (Ref 6, 14, 17, 36) indicate that the phenomenon is initiated as a thick slip band forming in a most conveniently oriented grain and then propagates to include adjoining grains, preserving the same spatial geometry (shear band). Research conducted for this study documents this phenomenon including the initial (up to a couple percent of elongation) and final (neck forming and destruction of sample) stages of zinc extrusion by the KOBO method. A sample with a structure as shown in Fig. 23 was subjected to stretching at an initial strain rate of $\dot{\varepsilon}=3 \times 10^{-4}$ $\mathrm{s}^{-1}$. The test was terminated after the sample reached $5 \%$ of elongation (Fig. 24), i.e., in the range, where the Lüders effect occurs. 

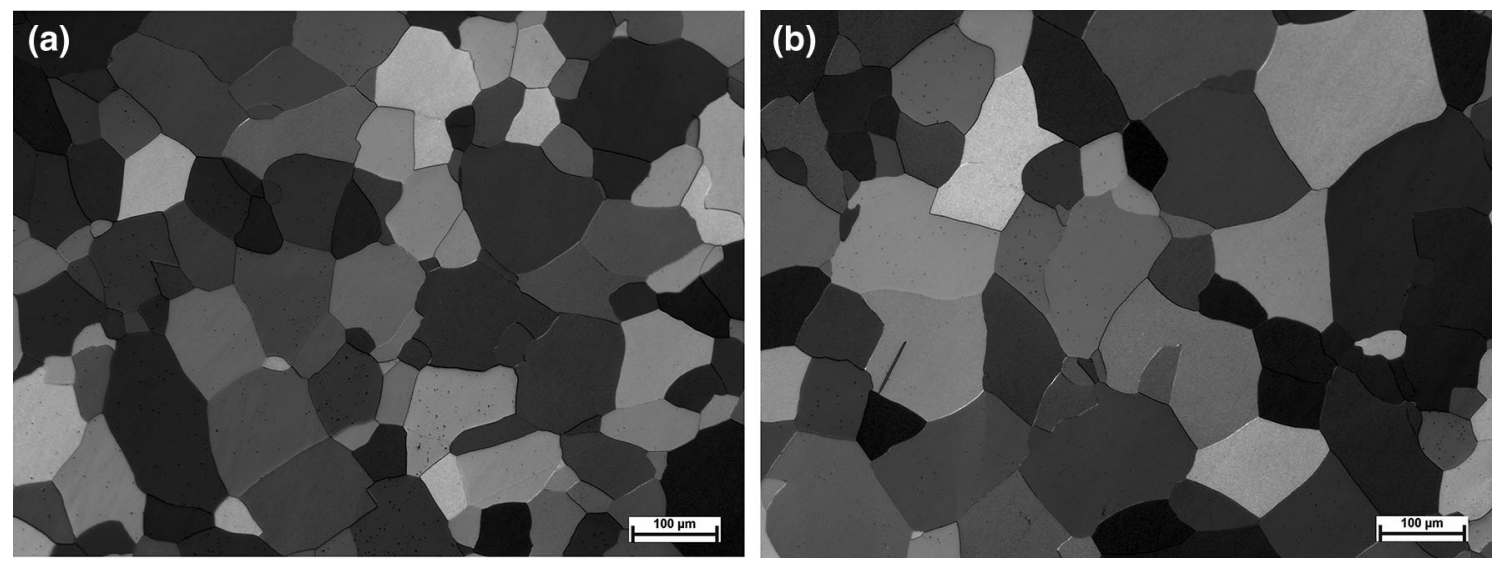

Fig. 23 Microstructure of zinc wire obtained as a result of the KOBO extrusion and exhibiting Lüders-type deformation during tensile testing. Extrusion rate $0.5 \mathrm{~mm} / \mathrm{s}$, reverse die oscillation frequency reduced from 5 to $4 \mathrm{~Hz}$, extrusion force $500 \mathrm{kN}$; transverse (a) and longitudinal (b) cross sections

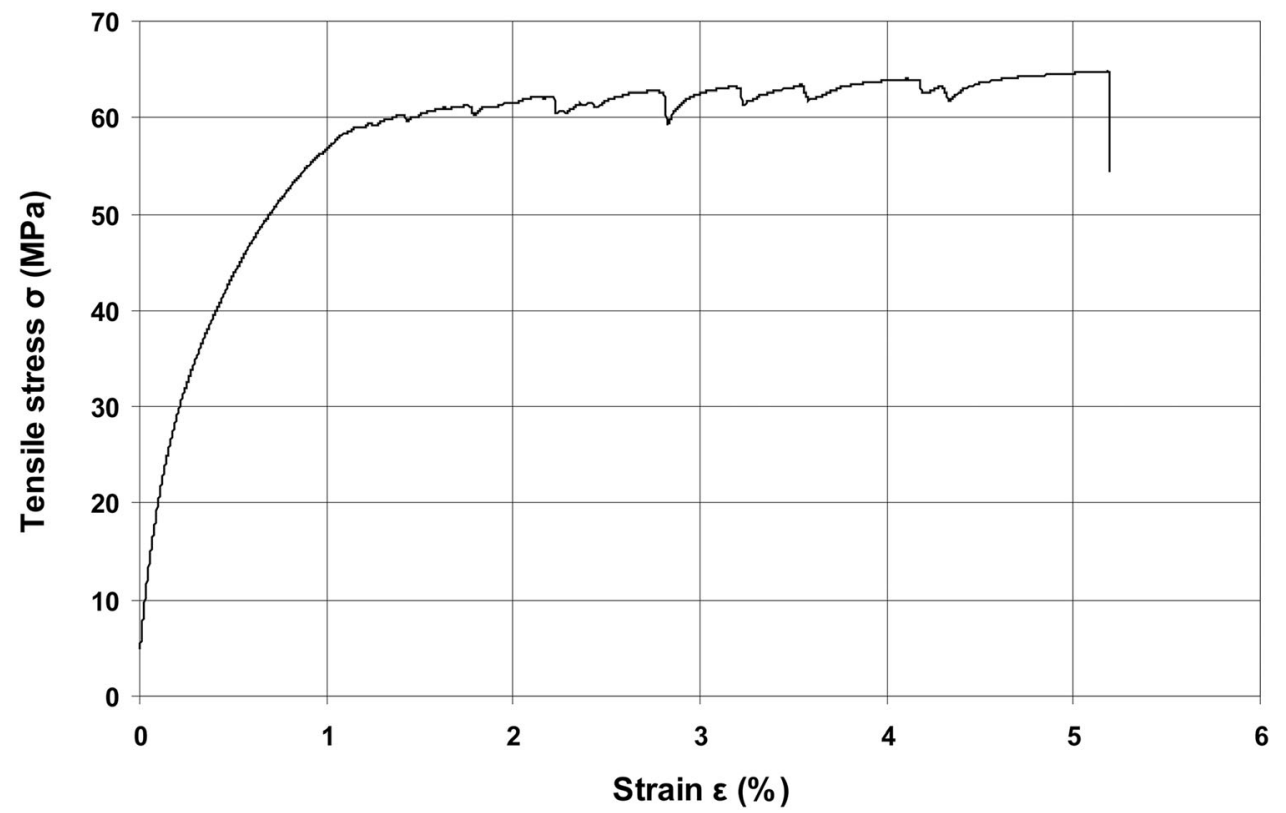

Fig. 24 Stress-strain curves of the KOBO extruded zinc. Process parameters as shown in Fig. 23. Strain rate during tensile testing $\dot{\varepsilon}=9 \times 10^{-4}$ $\mathrm{s}^{-1}$. The tensile test was performed up to $5 \%$ elongation.

The surface of the sample formed during stretching (Fig. 25) suggests that the Lüders effect is linked to intense propagation of interrupted localization. The effects of very intense deformation in the form of lens-like shapes, resembling deformation twins, which can be treated as elements of shear bands, are clearly visible.

Zinc extruded by the KOBO method at a rate of $0.5 \mathrm{~mm} / \mathrm{s}$ and constant die oscillation frequency of $5 \mathrm{~Hz}$, i.e., under the conditions of extrusion force dropping from 1000 to $700 \mathrm{kN}$, was also subjected to similar research. The process parameters promoted monotonic courses of stress-strain curves. A sample with a structure as shown in Fig. 26 was stretched to $2.5 \%$ of elongation and then observed with Nomarski contrast micro- scopy (Fig. 27). The localization of deformation effects were not found, instead traces of rotation of individual grains were observed, leading to a significant differentiation in their surface positioning against one another and suggesting a homogeneous deformation, defined as crystallographic slip, occurring within individual grains.

Figure 28, on the other hand, presents mechanical characteristics of zinc extruded by the KOBO method under conditions promoting the Lüders effect, where during tension sudden destruction (cracking) or, alternatively, neck forming occurs. Images of the samples representing these two extreme behaviors of zinc are presented in Fig. 29, while their structures revealed in the destroyed parts and presented in transverse cross 


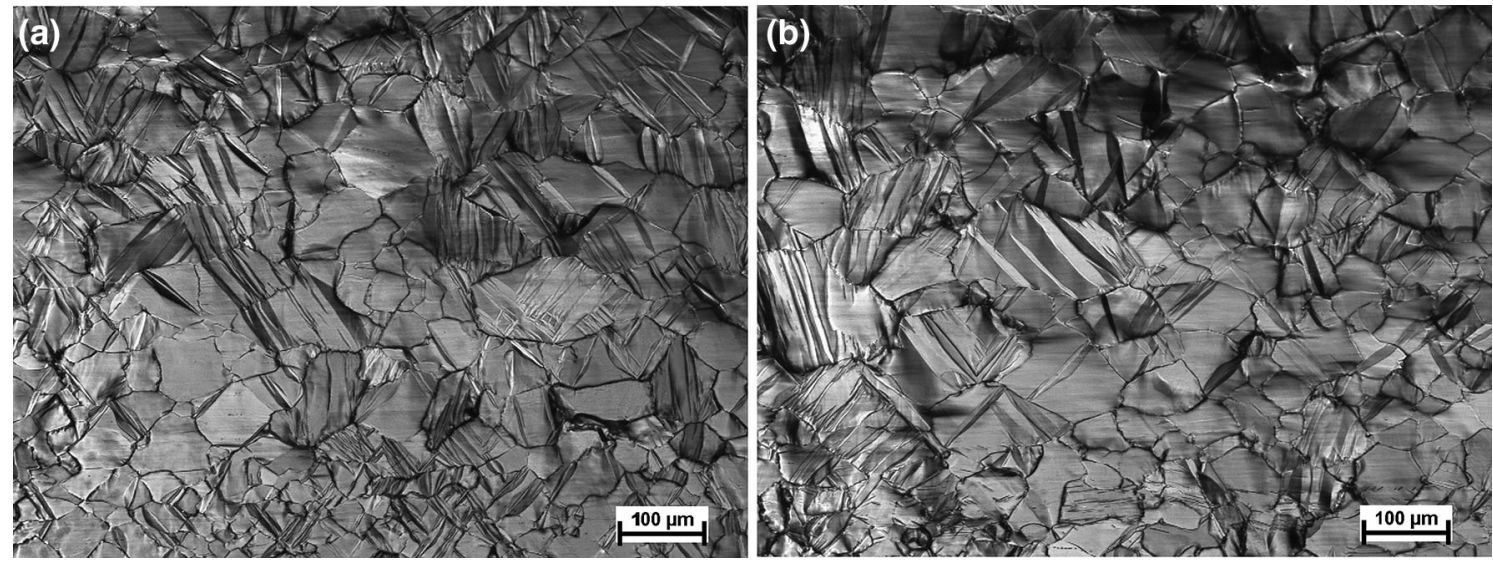

Fig. 25 Surface topography of a sample exhibiting Lüders-type deformation after tensile testing to about 5\% of elongation (see also Fig. 23 and 24); transverse (a) and longitudinal (b) cross sections
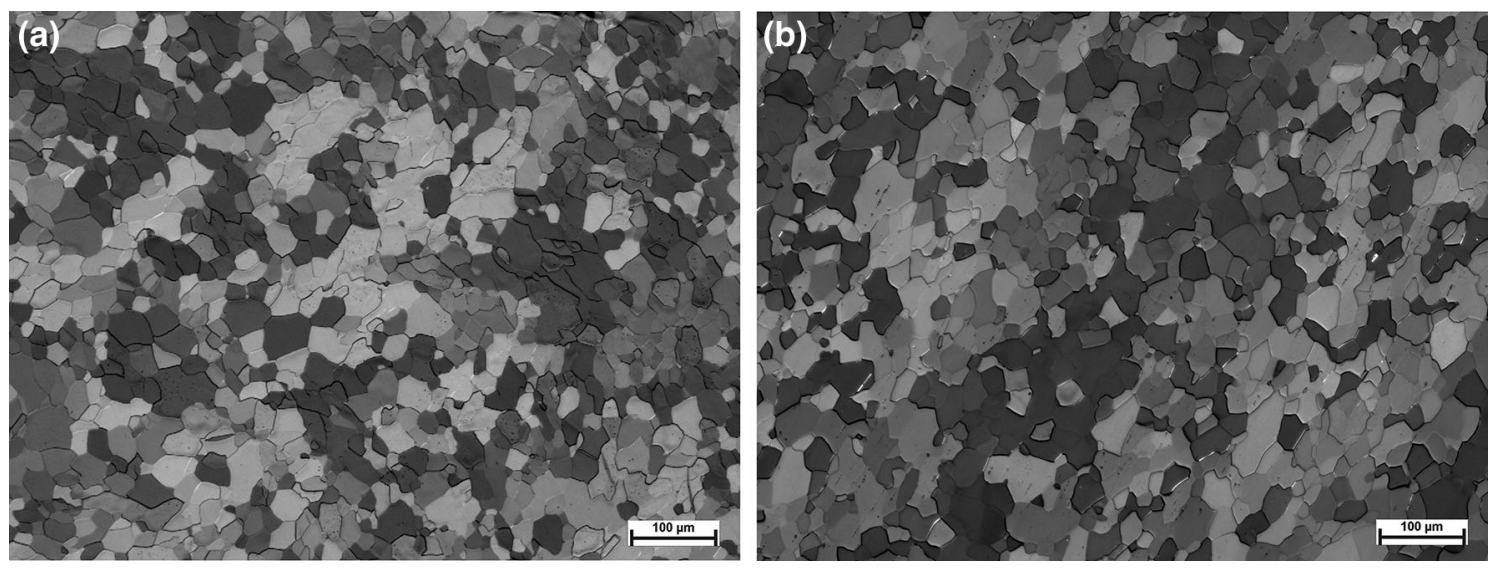

Fig. 26 Microstructures from the end of a zinc wire, obtained as a result of the KOBO extrusion and exhibiting homogeneous deformation during tensile testing. Extrusion rate $0.5 \mathrm{~mm} / \mathrm{s}$, reverse die oscillation frequency $5 \mathrm{~Hz}$, extrusion force dropping from 1000 to $700 \mathrm{kN}$; transverse (a) and longitudinal (b) cross sections
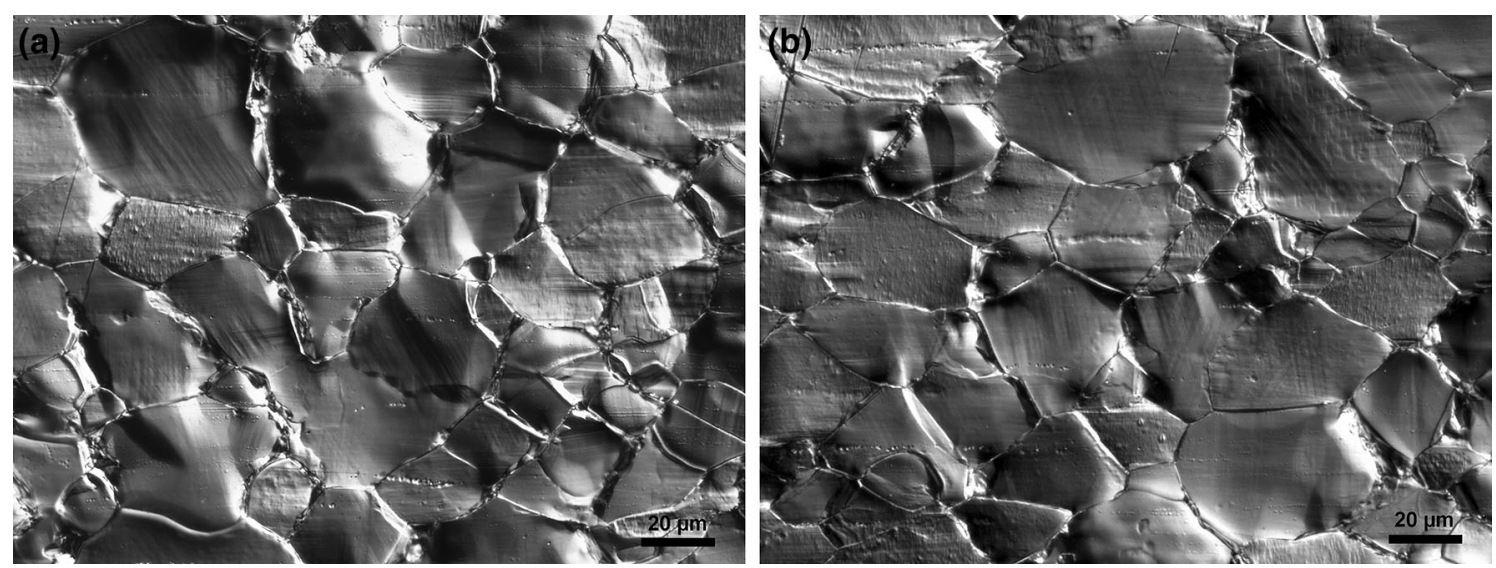

Fig. 27 Surface topography of a zinc sample not exhibiting Lüders-type deformation after tensile testing up to about $2.5 \%$ of elongation; transverse (a) and longitudinal (b) cross sections. The KOBO extrusion process parameters as shown in Fig. 26 


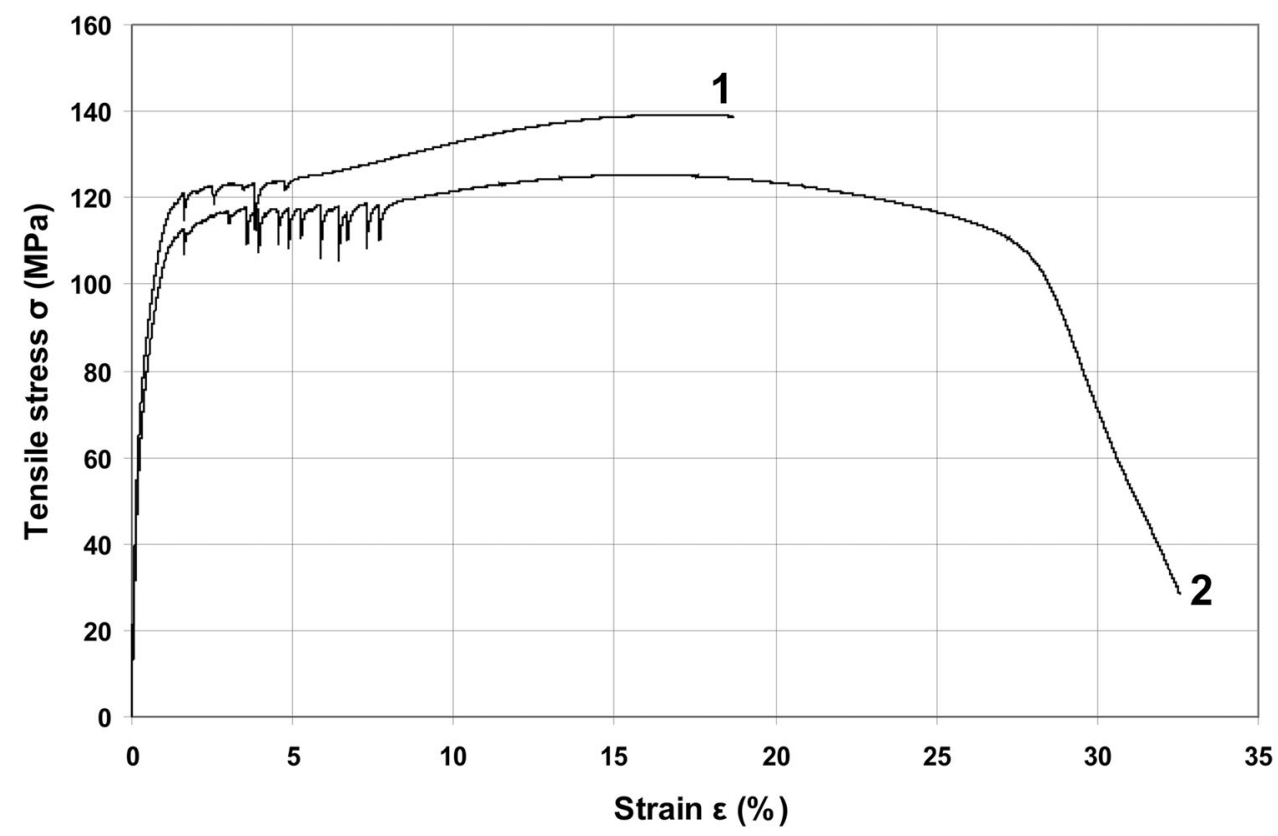

Fig. 28 Impact of strain rate on stress-strain curves of the KOBO extruded zinc. Extrusion rate $0.5 \mathrm{~mm} / \mathrm{s}$, reverse die oscillation frequency 5 $\mathrm{Hz}$, extrusion force dropping from 600 to $450 \mathrm{kN}$. Strain rate during tensile testing $\dot{\varepsilon}: 5 \times 10^{-4} \mathrm{~s}^{-1}$ (1) and $1 \times 10^{-4} \mathrm{~s}^{-1}(2)$

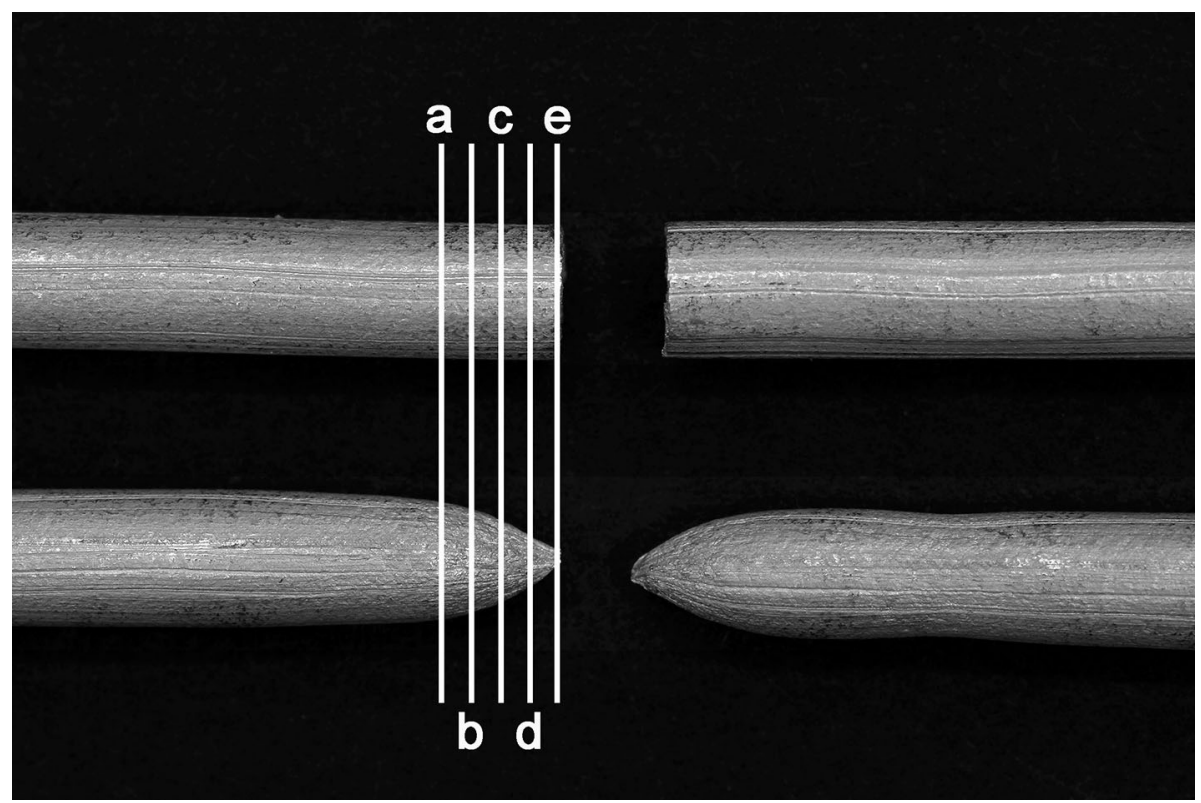

Fig. 29 Images of the KOBO extruded wire (conditions of the process are given in the caption of Fig. 28) after tensile testing, documenting two extreme behaviors of zinc. The samples for structural observations presented in Fig. 30 and 31 were taken from the marked areas

sections are shown in Fig. 30 and 31. It is noticeable that the development of the neck leads only to grain elongation, but does not cause their fragmentation, even though the images of transverse cross sections might make such an impression. Localization of deformation promoting neck development (Fig. 29-bottom sample) or fracture (Fig. 29-upper sample) depends on the strain rate during tensile test. When the process is slow, it is accompanied by plastic flow in the neck.

\section{Conclusions}

1. The possibility to control mechanical properties of pure zinc via relevant KOBO extrusion parameters was proved. 

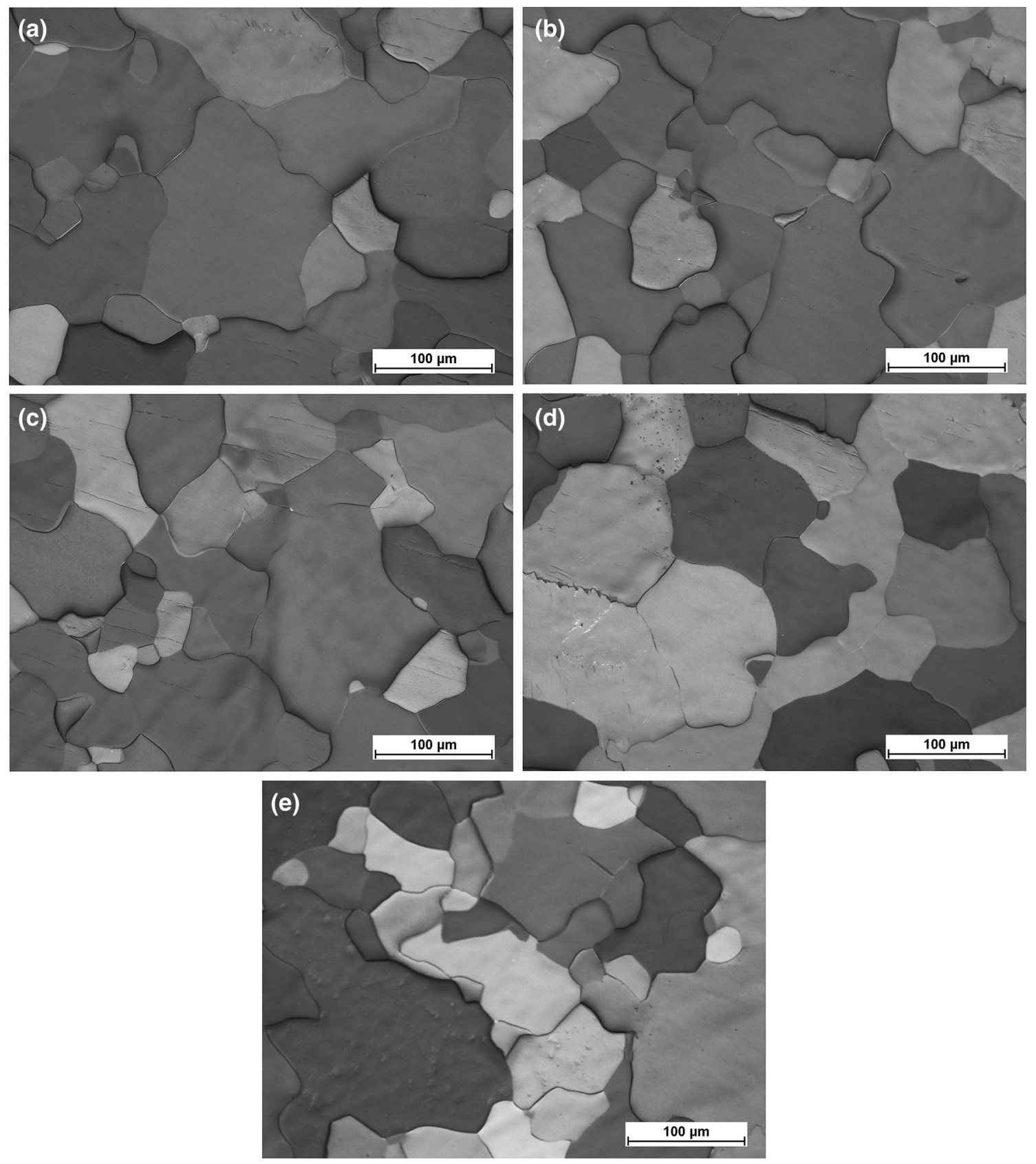

Fig. 30 Microstructures of samples demonstrate cracking during tensile tests taken from areas marked in Fig. 29

2. Depending on the values of the KOBO extrusion parameters, zinc shows highly differentiated mechanical properties, either Lüders-type instability or monotonic stressstrain curves.

3. The tendency for the Lüders phenomenon depends on the level of the KOBO extrusion force. Low values of force (from 600 to $300 \mathrm{kN}$ for the frequencies of 3 and $5 \mathrm{~Hz}$ ) promotes Lüders-type deformation, and high force values result in a monotonic course of the stress-strain curve.

4. It was confirmed that zinc extrusion by the KOBO method at constant speed and constant extrusion force guarantees identical mechanical properties throughout the whole product.
5. High strain rate sensitivity of zinc formerly extruded by the KOBO method indicates its superplastic-like behavior.

6. Fragmentation of grains as the main cause of Lüders-type instability does not seem to be proved true by the research results.

7. Transmission electron microscopy observations of the KOBO extruded zinc indicated low numbers of dislocations and high density of point defect clusters.

8. It was established that 'strips,' equivalent to shear bands, revealed in the structure of the KOBO extruded zinc, are the places of point defects generation and their evolution into rows of clusters, which decides about mechanical 

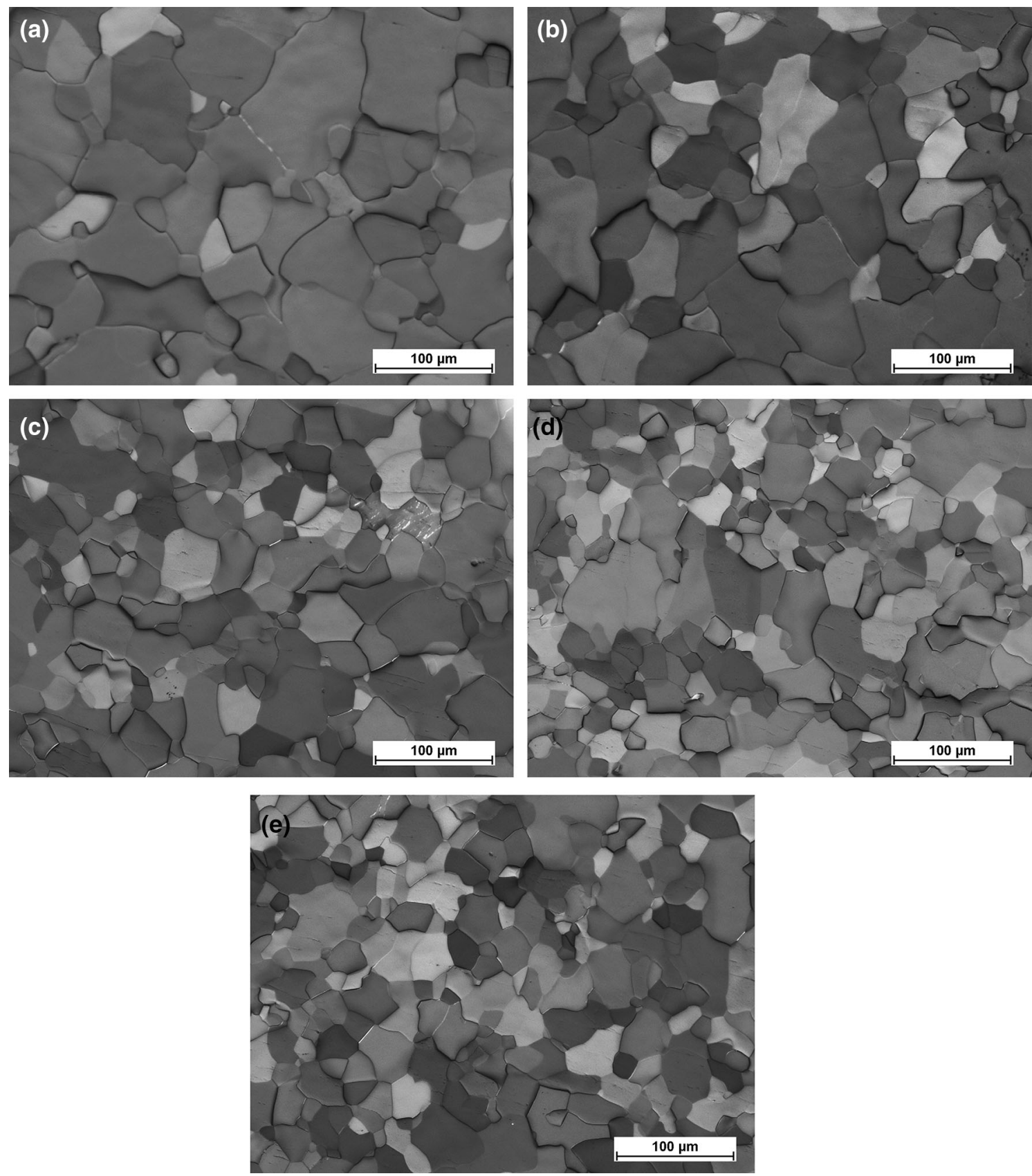

Fig. 31 Microstructures of samples demonstrate necking during tensile tests taken from areas marked in Fig. 29

properties of the material. Unlike well-formed clusters, responsible for smooth stress-strain curves, strips with over-saturated point defects lead to Lüders-type mechanical instability.

\section{Acknowledgments}

The authors are pleased to express their gratitude to Professors Andrzej Korbel, Ludwik Błaż and Krzysztof Pieła for their experimental collaboration and discussions.

\section{Open Access}

This article is licensed under a Creative Commons Attribution 4.0 International License, which permits use, sharing, adaptation, distribution and reproduction in any medium or format, as long as you give appropriate credit to the original author(s) and the source, provide a link to the Creative Commons licence, and indicate if changes were made. The images or other third party material in this article are included in the article's Creative Commons licence, unless indicated otherwise in a credit line to the material. If material is not included in the article's Creative Commons licence and your intended use is not permitted by statutory regulation or exceeds the permitted use, you will need to obtain permission 
directly from the copyright holder. To view a copy of this licence, visit http://creativecommons.org/licenses/by/4.0/.

\section{References}

1. R.Z. Valiev, R.K. Islamgaliev and I.V. Alexandrov, Bulk Nanostructured Materials from Severe Plastic Deformation, Progr. Mater. Sci., 2000, 45, p 103-189

2. N. Tsuji, Y. Saito, S.H. Lee and Y. Minamino, ARB (Accumulative Roll-Bonding) and Other New Techniques to Produce Bulk Ultrafine Grained Materials, Adv. Eng. Mater., 2003, 5, p 338-344

3. A. Rosochowski, Processing Metals by Severe Plastic Deformation, Solid State Phen., 2005, 101-102, p 13-22

4. A. Korbel and W. Bochniak, Method of plastic forming of materials, U.S. Patent No 5,737,959 (1998), European Patent No 0711210 (2000)

5. A. Korbel and W. Bochniak, Refinement and Control of the Metal Structure Elements by Plastic Deformation, Scr. Mater, 2004, 51, p 755-759

6. A. Korbel and W. Bochniak, Lüders Deformation and Superplastic Flow of Metals Extruded by KOBO Method, Philos. Mag., 2013, 93, p 1883-1913

7. A. Korbel, W. Bochniak, P. Ostachowski, A. Paliborek, M. Łagoda and A. Brzostowicz, A New Constitutive Approach to Large Strain Plastic Deformation, Int. J. Mater. Res., 2016, 107, p 44-51

8. A. Korbel and W. Bochniak, Stratified Plastic Flow in Metals, Int. J. Mech. Sci., 2017, 128-129, p 269-276

9. M. Kiritani, K. Yasunaga, Y. Matsukawa and M. Komatsu, Plastic Deformation of Thin Metal Foils Without Dislocations and Formation of Point Defects and Point Defect Clusters, Rad. Eff. Defect. Solid., 2002, 157, p 3-24

10. T. Byun and K. Farrell, Plastic Instability in Polycrystalline Metals After Low Temperature Irradiation, Acta Mater, 2004, 52, p 1597 1608

11. R. Maddin and A. Cottrell, Quench Hardening in Aluminium Single Crystals, Philos. Mag., 1955, 46, p 735-743

12. R. Smallman and K. Westmacott, Structure of Quenched and Irradiated Metals, J. Appl. Phys., 1959, 30, p 603-616

13. R.T. Qu, Z.Q. Liu, G. Wang and Z.F. Zhang, Progressive Shear Band Propagation in Metallic Glasses Under Compression, Acta Mater. 2015, 91, p 19-33

14. J.W. Wyrzykowski and M.W. Grabski, Lüders Deformation in Ultrafine-Grained Pure Aluminium, Mater. Sci. Eng., 1982, 56, p $197-200$

15. K. Pieła, The Occurrence and Characteristics of Luders Deformation in Polycrystalline Zinc, Archiv. Metall., 2001, 46, p 43-52

16. P.L. Sun, C.Y. Yu, P.W. Kao and C.P. Chang, Influence of Boundary Characters on the Tensile Behavior of Sub-Micron-Grained Aluminum, Scr. Mater., 2005, 52, p 265-269

17. P.C. Hung, P.L. Sun, C.Y. Yu, P.W. Kao and C.P. Chang, Inhomogenous Tensile Deformation in Ultrafine-Grained Aluminum, Scr. Mater, 2005, 53, p 647-652

18. C.Y. Yu, P.W. Kao and C.P. Chang, Transition of Tensile Deformation Behaviors in Ultrafine-Grained Aluminum, Acta Mater, 2005, 53, p 4019-4028

19. N. Tsuji, Y. Ito, Y. Saito and Y. Minamino, Strength and Ductility Of Ultrafine Grained Aluminum and Iron Produced by $\mathrm{ARB}$ and Annealing, Scr. Mater., 2002, 47, p 893-899
20. D. Loyd and L. Morris, Luders Band Deformation in a Fine Grained Aluminium Alloys, Acta Metall., 1977, 25, p 857-861

21. C.Y. Yu, P.L. Sun, P.W. Kao and C.P. Chang, Evolution of Microstructure During Annealing of Severely Deformed Aluminum, Mater. Sci. Eng. A, 2004, 366, p 310-317

22. Y. Wang, M. Chen, F. Zhou and E. Ma, High Tensile Ductility in Nanostructured Metal, Nature, 2002, 419, p 912-915

23. Y. Estrin and A. Vinogradov, Extreme Grain Refinement by Severe Plastic Deformation: A Wealth of Challenging Science, Acta Mater, 2013, 61, p 782-817

24. A. Korbel, J. Pospiech, W. Bochniak, A. Tarasek, P. Ostachowski and J. Bonarski, New Structural and Mechanical Features of Hexagonal Materials after Room Temperature Extrusion by KoBo Method, Int. J. Mater. Res., 2011, 102, p 464-473

25. V.S. Ananthan and E.O. Hall, Microscopic Shear Bands at Lüders Front in Mild Steel, Scr. Metall., 1987, 21, p 519-520

26. W. Bochniak, The Effect of Prestrain and Recrystallization Conditions on the Occurrence of the Lüders Phenomenon in CuSn2 Alloy, Mater. Sci. Eng. A, 1989, 112, p 151-155

27. W. Bochniak, The Microstructure of Lüders Band in Cu-Sn2 Alloy, Scr. Metall., 1989, 23, p 519-522

28. A. Korbel, Structural and Mechanical Aspects of Homogeneous and Non-Homogeneous Deformation in Solids. Localization and Fracture Phenomena in Inelastic Solids. International Centre for Mechanical Sciences, Courses and Lectures - No. 386, ed. by P. Perzyna - Polish Academy of Sciences, Springer Wien New York 1998, p 21-98

29. F. Chmelík, Z. Trojanová, P. Lukáč and Z. Převorovský, Acoustic Emission from Zinc Deformed at Room Temperature. Part I-The Influence of Strain Rate on Deformation Behavior and Acoustic Emission in Pure Zinc, J. Mater. Sci. Let., 1993, 12, p 1086-1087

30. K. Pieła, Strain Rate Sensitivity of Zinc at the Temperature of Deformation, Ores Met., 1982, 27, p 361-367. (in Polish)

31. K. Pieła, Lüders Deformation in Polycrystalline Zinc. Scientific Papers of Kielce University of Technology - Mechanics 2000, 72, p 197-202 (in Polish)

32. A. Korbel, W. Bochniak, P. Ostachowski and L. Błaż, Visco-Plastic Flow of Metal in Dynamic Conditions of Complex Strain Scheme, Metall. Mater. Trans. A, 2011, 42, p 2881-2897

33. A. Paliborek, The Mechanical Characteristics of Zinc After Large Plastic Deformation and its Structural Interpretation. Ph.D. Thesis. AGH - University of Science and Technology, Cracow, 2014 (in Polish)

34. A. Korbel, W. Bochniak, J. Borowski, L. Błaż, P. Ostachowski and M. Łagoda, Anomalies in Precipitation Hardening Process of 7075 Aluminum Alloy Extruded by KOBO Method, J. Mater. Proc. Technol., 2015, 216, p 160-168

35. W. Bochniak, P. Ostachowski, A. Korbel and K. Pieła, Superplastic Flow of Metals Extruded by KOBO Method, Mater. Sci. Forum, 2011, 667-669, p 1039-1044

36. C.Y. Yu, P.L. Sun, P.W. Kao and C.P. Chang, Mechanical Properties of Submicron-Grained Aluminum, Scr. Mater., 2005, 52, p 359-363

Publisher's Note Springer Nature remains neutral with regard to jurisdictional claims in published maps and institutional affiliations. 